\title{
The Biased Bystander: How Homophobia Affects Intervention in Physical Fights
}

\author{
R. Kyle Saunders
}

Follow this and additional works at: https://researchrepository.wvu.edu/etd

\section{Recommended Citation}

Saunders, R. Kyle, "The Biased Bystander: How Homophobia Affects Intervention in Physical Fights" (2016). Graduate Theses, Dissertations, and Problem Reports. 6572.

https://researchrepository.wvu.edu/etd/6572

This Thesis is protected by copyright and/or related rights. It has been brought to you by the The Research Repository @ WVU with permission from the rights-holder(s). You are free to use this Thesis in any way that is permitted by the copyright and related rights legislation that applies to your use. For other uses you must obtain permission from the rights-holder(s) directly, unless additional rights are indicated by a Creative Commons license in the record and/ or on the work itself. This Thesis has been accepted for inclusion in WVU Graduate Theses, Dissertations, and Problem Reports collection by an authorized administrator of The Research Repository @ WVU. For more information, please contact researchrepository@mail.wvu.edu. 


\title{
The Biased Bystander: How Homophobia Affects Intervention in Physical Fights
}

\author{
R. Kyle Saunders \\ Thesis submitted \\ to the Eberly College of Arts and Sciences \\ at West Virginia University \\ in partial fulfillment of the requirements for the degree of \\ Master of Arts in \\ Sociology
}

\author{
Lisa Dilks, Ph.D., Chair \\ Jason Manning, Ph.D. \\ James Nolan, Ph.D.
}

Department of Sociology and Anthropology

Morgantown, West Virginia

2016

Keywords: bystander, intervention, LGBT, attitudes, bias, helping behavior, prosocial behaviors

Copyright 2016 R. Kyle Saunders 


\title{
The Biased Bystander: How Homophobia Affects Intervention in Physical Fights
}

\author{
R. Kyle Saunders
}

Sociologists, criminologists and psychologists have offered a number of theories to understand bystander intervention in emergency situations in general. Most notably, the bystander effect argues that as the number of bystanders to an incident increases, the less likely someone is to intervene. However, the likelihood of intervention could also be dependent on the personal biases of the observers. A bystander's contempt or dislike for particular victims (homosexuals, minorities, women, etc.) may influence his or her willingness to intervene. This research explores, through the use of vignette experiments, the extent to which a bystander's homophobia influences their willingness to intervene on behalf of a homosexual victim in a physical altercation. The research design also analyzes whether such biases interact with the presence (or absence) of other bystanders to the event. Understanding if there is a relationship between personal biases and bystander intervention contributes to our theoretical and empirical understanding of the bystander effect. The results show that bias does influence helping behaviors, and, in some scenarios, bias supersedes the strength of the bystander effect. Further, there seems to be a strong social desirability effect where participants are most likely to intervene on behalf of a gay victim as opposed to a straight victim, particularly when others are present. Results involving the participant's sex echoes previous literature. Finally, a new finding on the social desirability scale is found in two of the three types of intervention. 


\section{Table of Contents}

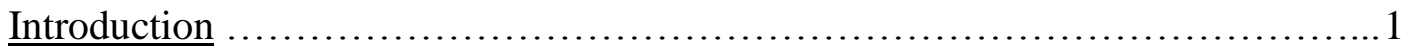

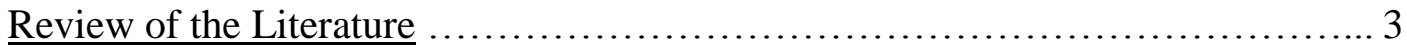

Socioecological Developmental Model of Prosocial Behaviors ............ 3

Familial and Social Factors ..................................... 5

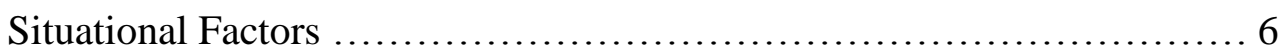

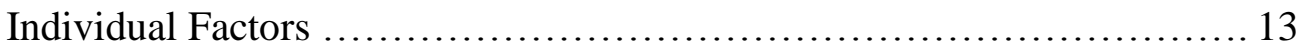

Examining the Role of Sexual Orientation on Prosocial Behavior .................. 15

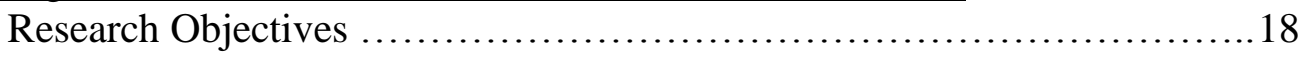

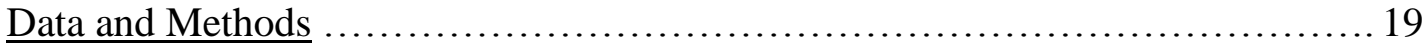

Participants ..................................................... 19

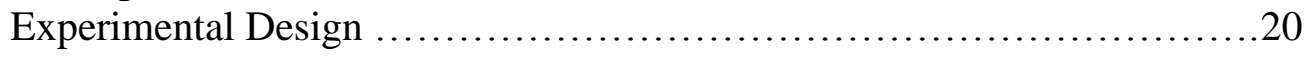

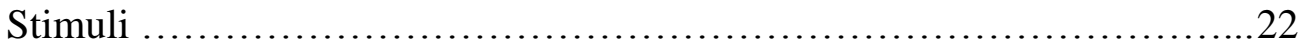

Variables and Measurements ....................................... 22

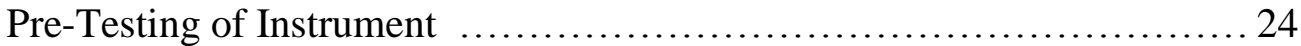

\section{$\underline{\text { Results }}$}

Analysis 1: Effect of Perpetrator/Victim Dyad on Bystander Intervention ..27

Analysis 1: Discussion and Implications ............................. 31

Analysis 2: Effect of Individual Biases on Bystander Intervention ...........34

Analysis 2: Discussion and Implications ........................... 37

Analysis 3: The Interactive Effect of Bias within Conditions .............. 39

Analysis 3: Discussion and Implications .......................... 42

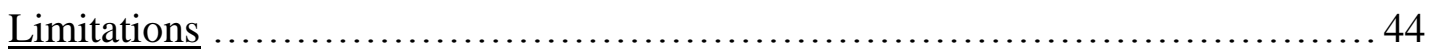

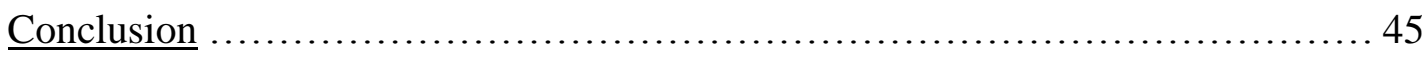

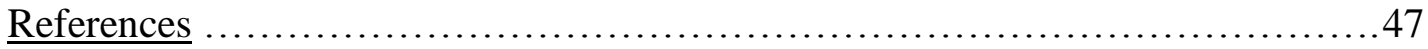

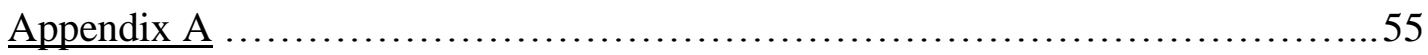




\section{$\underline{\text { INTRODUCTION }}$}

When fights occur outside bars, nightclubs or sporting events, the numbers of bystanders usually outnumber the individuals involved in the actual altercation. But why do bystanders choose to watch or leave rather than act? The Kitty Genovese case, albeit criticized $^{1}$, pushed this topic into the interests of researchers with the parable of 38 neighbors who watched her rape and murder without helping or calling the police. Social psychologists Latane and Darley (1970) argued that Genovese's neighbors failed to get help due to the bystander effect. This phenomenon states that as the number of bystanders to an event increases the likelihood of any one observer intervening decreases. Individuals in groups tend to diffuse the responsibility for offering or calling for assistance (Latane and Darley 1970). However, there are a plethora of variables other than bystander group size that influence intervention.

Variables that affect the bystander on individual, situational, and larger societal levels have been shown to significantly influence rates of intervention. The enormous list of variables tested continues to grow even after decades of bystander research: masculinity (Tice and Baumeister 1985), pluralistic ignorance (Latane and Darley 1970; Bjerring, Hansen, and Pedersen 2014), confusion of responsibility (Weaver, Moskowitz, and Darley 2002), evaluation apprehension (Latane and Darley 1970), diffusion of responsibility (Latane and Darley 1970; Latane and Nida 1981), reciprocity (Axelrod and Hamilton 1981; Trivers 1971; Bhatnager and Machanda 2013), social group membership (Latane and Rodin 1969; Abbott and Cameron 2014; Shotland and Straw 1976; Levine 1999) cost (Fischer, Greitemeyer, Pollozek, and Frey 2006), clarity (Latane and Nida

\footnotetext{
${ }^{1}$ For criticisms of the parable of the Kitty Genovese case see Manning and Collins (2007) and Lurigio (2015)
} 
1981; Clark and Word 1974; Solomon, Solomon, and Stone 1978), sex (Latane and Dabbs 1975), age (Staub 1970; Ross 1971), emergencies (Harari et al. 1985; Schwartz and Gottieb 1976), severity (Fischer et al. 2006; Nicksa 2014), stigma (Ungar 1979), and blame (Lyons 2006; Rayburn, Mendoza, and Davison 2003). Although there is not a dearth of research on bystander intervention, there are variables that have been overlooked or only slightly measured, particularly with regard to those factors occurring at the level of the individual.

One factor that has not been thoroughly explored in the context of bystander intervention is the role of individual biases. A bystander's contempt or dislike for particular others (homosexuals, minorities, women, etc.) may influence his or her willingness to intervene. This research examines whether or not individual biases - in this case, homophobia - supersede the influence of the bystander effect. More specifically, does an individual's acceptance of a victim's sexual orientation have a stronger influence on their likelihood to intervene than bystander group size? This study employs vignette experiments that manipulate both the number of bystanders witnessing a physical fight as well as the sexual orientations of the victim and offender involved in the altercation. This study utilizes the Attitudes Toward Lesbians and Gay Men Scale developed by Herek (1994) to capture participants' biases. Understanding the rationalizations, for example, of a homophobic person who chooses not to intervene can help lay the foundation to a new theoretical knowledge of how biases influence action or inaction and further our understanding of bystander behavior. 


\section{REVIEW OF THE LITERATURE}

\section{Socioecological Developmental Model of Prosocial Behaviors}

Prosocial behaviors are "actions that are considered beneficial to others and as having positive social consequences" (DeLamater, Myers and Collett 2015: 344). Carlo and Randall (2001) developed a socioecological developmental model of prosocial behaviors by integrating a number of concepts from previous literature. This model uses ecological theory (Bronfenbrenner 1979), social cognitive theory (Bandura 1986) as well as other models of prosocial behavior (Eisenberg 1986; Knight, Bernal, and Carlo 1995; Latane and Darley 1970; Staub 1978, 1979). The purpose of the model is to attempt to account for the individual, social, ecological, and interpersonal influences of this kind of behavior. Carlo and Randall (2001) acknowledge three broad categories of variables that act as influences: cognitive and emotive (e.g. individual); family and social; and situational. Family and social variables include agents of socialization: "family (e.g., primary caregivers, siblings, extended family members), peers (e.g., friends, acquaintances, peer norms and expectations), and culture (e.g., gender, schools, media, law, norms)" (Carlo and Randall 2001: 156). Situational characteristics may include the number of bystanders, the severity of the event, clarity of need, physical attractiveness of the individuals involved in the event, the identity of the target person, and ease-of-escape. Finally, cognitive and emotive variables include individual level factors such as selfefficacy, values, reasoning, attributions, self-concept, perceptions, and memory processes.

These three factors - social, situational, and individual - not only affect bystander behavior on their own accord but also collectively. Social psychologist Kurt Lewin 
claimed that the environment surrounding an individual influences their behavior. Levin and Nolan (2011) offer a mathematical representation, $B=f\left(P, E_{1 s}, E_{s c}\right)$, of Lewin's idea to show visually the relationship between an individual, their surroundings, and their sociocultural (See Figure 1 for design).

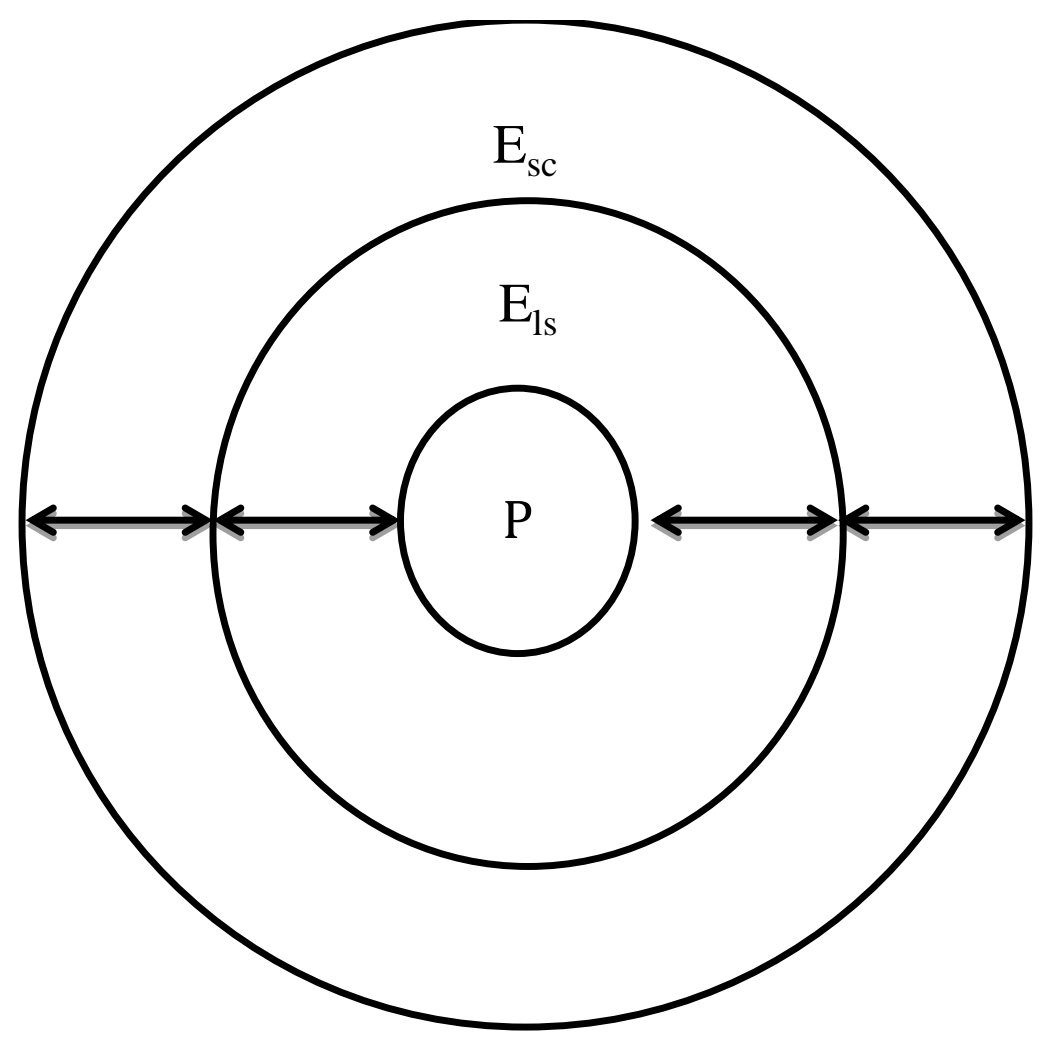

\section{Figure 1. The situationist perspective (Levin and Nolan 2011:42)}

In Figure 1, $\mathrm{P}$ is the individual (i.e., cognitive and emotive factors), $\mathrm{E}_{\mathrm{ls}}$ is the immediate surroundings (i.e., situational factors), and $\mathrm{E}_{\mathrm{sc}}$ is the sociocultural environment (i.e., social factors). As Levin and Nolan (2011: 43) state, “... a person (P), has a disposition or temperament that we carry with us into each local situation $\left(\mathrm{E}_{\mathrm{ls}}\right)$. Norms, 
values, expectations and environmental conditions in the local situation $\left(\mathrm{E}_{\mathrm{ls}}\right)$ may conform to or conflict with the larger environmental conditions ( $\left.\mathrm{E}_{\mathrm{sc}}\right) . "$

\section{Familial and Social Factors}

The effects of socialization, peers, and family on prosocial behaviors have been explored from multiple points of view. Contextual background variables in regards to family and socialization (e.g., parenting style, stable relationships) have been shown to significantly influence the appearance and sustainment of prosocial behaviors (Eisenberg 1986; Baumrind 1991; Dekovic and Janssens 1992; Lamborn, Mounts, Steinberg, and Dornbusch 1991; Eisenberg, Fabes, and Spinrad 1998). For example, Staub (1979) found that among children, prosocial television programs and the coaching of prosocial behaviors increases these tendencies. Baunmrind's (1991) results show that adolescents who had authoritative parents had significantly higher prosocial behavior tendencies than adolescents with unengaged parents. The closeness of relationships is also related to prosociality (Eisenberg et al. 1998). Research finds that children as young as 5 years old report more sympathy toward a friend than an acquaintance (Costin and Jones 1992). Additionally, it is not just liking an individual (Costin and Jones 1992) that causes this increase, but also loyalty through the perceived reciprocity requirements of friendship (Birch and Billman 1986).

Carlo, Roesch and Koller (1999) illustrate the relationship between culture and levels of prosocial tendencies. In their study, Brazilian students show higher levels of approval-oriented prosocial moral reasoning than their American counterparts (Carlo et al. 1999). Additionally, gender significantly influences prosocial reasoning with men showing higher levels of prosocial moral reasoning than women (Carlo et al. 1999; Eagly 
and Crowley 1986; Whiting and Edwards 1974; Lennon and Eisenberg 1987). Merrens's (1973) results suggest that the bystander effect is more influential in urban areas than rural. For example, individuals from mid-western towns displayed significantly more helping behaviors than their counterparts who lived in urbanized cities, such as New York City (Merrens 1973). However, these factors are only a subsection of what influences prosocial behavior.

\section{Situational Factors}

The details surrounding the situation of an observed event are highly related to increases and decreases in bystander intervention. For instance, as the severity of an event increases, the strength of the bystander effect decreases (Harari et al. 1985). How ambiguous an event is can either inhibit or clarify bystanders' evaluation of the situation (Fischer, Greitemeyer, Kastenmuller, Krueger, Vogrincic, Frey, Heene, Wicher, and Kainbacher 2011; Nicksa 2014). Further, although the bystander effect states the more observers there are, the less likely intervention is, there are situations where having more bystanders increases intervention (Harari et al. 1985; Schwartz and Gottlieb 1976; Clark and Word 1974; Checkroun and Brauer 2002). A more in-depth examination of these situational variables is needed to understand fully how they influence bystander intervention on their own and how they interact with other factors.

Bystander Apathy

Research in psychology and social psychology has explored numerous factors that explain when and how bystanders will react in emergency situations in general (Harari et al. 1985; Schwartz and Gottlieb 1976; Fischer et al. 2006) and physical altercations in particular (Banyard 2008; Laner, Benin and Ventrone 2001; Lyons 2006; Shotland and 
Straw 1976). Arguably the most famous and important explanation for bystander (in)action is the bystander effect. Latane and Darley (1970) developed a five-step psychological model for bystander intervention: the bystander must (1) notice the situation, (2) believe the situation to be an emergency, (3) develop a sense of responsibility, (4) believe that she or he has skills to succeed and (5) come to the conclusion to help. Further, Latane and Darley (1970) concluded that there are three explanatory factors for the bystander effect which may disrupt the completion of the model: the diffusion of responsibility, pluralistic ignorance, and evaluation apprehension. Diffusion of responsibility happens when an individual divides the responsibility of helping among all bystanders, thus, lowering their likelihood to do so and their sense of responsibility (Latane and Darley 1970; Fischer et al. 2011). Pluralistic ignorance occurs when a bystander of an event interprets other bystanders as being unconcerned with the situation, which causes inaction to seem more desirable to avoid embarrassment or failure (Bjerring et al. 2014; Wisely 2007; Latane and Darley 1970; Fischer et al. 2011). Evaluation apprehension refers to the fear of being criticized or judged by others for acting, not acting, or making a mistake (Fischer et al. 2011). Evaluation apprehension does hold a strong influence on bystander behavior (Watson and Friend 1969). Watson and Friend (1969) found that individuals who scored high on their Fear of Negative Evaluation Scale become increasingly nervous in situations where they will be evaluated, which, in turn, coerces them to conform to actions or behaviors for social approval. Previous research backs this claim that some individuals are more anxious than others in social interaction, which causes them to be persuadable (Sears 1967) and more aware of others' evaluation of themselves (Diggory 1966). 
Although Latane and Darley's (1970) account of the bystander effect is the most widely referenced, others have offered modifications to the process. For example, rather than diffusion of responsibility Cacioppo, Petty, and Losch (1986) argue that confusion of responsibility may inhibit bystander intervention. This account of the bystander effect argues that would-be helpers refrain from doing so while in the presence of other bystanders because they do not want to be interpreted as a perpetrator of the event (Cacioppo et al. 1986).

Research conducted both in laboratory experiments and in the field support the existence of a bystander effect (Shaffer, Rogel, and Hendrick 1975). However, results have found a few variables that diminish the bystander effect: young bystander age (Staub 1970), low ambiguity of the event (Clark and Word 1972), low ability to successfully intervene by other bystanders (Bickman 1971), or a lack of communication among bystanders (Latane and Darley 1976). For example, Fischer et al. (2011) states that the bystander effect's strength varies with the perceived danger the victim is in when determining to intervene or not. Furthermore, as the ambiguity of the situation increases intervention likelihood decreases (Clark and Word 1974; Solomon, et al. 1978). Christy and Voigt (1994) and Harari's et al. (1985) find that violent situations, such as child abuse, create a clear need for assistance and erase ambiguity concerns thereby increasing intervention rates.

Additionally, private relationships (e.g. friendships) seem to dissolve the bystander effect (Latane and Rodin 1969). Latane and Rodin (1969) analyzed how quickly individuals and two-person groups helped a person they heard fall. The twoperson groups were less likely to help than those who were alone; however, when the pair 
were friends the bystander effect was not as strong and they helped significantly faster than the pair who were strangers (Latane and Rodin 1969). Relatedly, Latane and Darley (1976) found that when there was no communication between bystanders $70 \%$ helped the victim within one minute, whereas approximately $40 \%$ helped when there was full communication. The bystander effect also seems to lose its influence when successful intervention may require more than one bystander to intervene (Greitemeyer and Mugge 2013; 2014).

A number of demographic characteristics also influence the strength of the bystander effect. Smith, Smythe, and Lien (1972) found significant differences in intervention rates when they manipulated the participant being with a similar, inactive bystander, 5\% intervened, and a dissimilar, inactive bystander, 35\% intervened. Ross (1971) examined the effect of the age of other inactive bystanders on intervention. The subjects' responded much more rapidly when the inactive bystander was a child opposed to when they were an adult (Ross 1971). Both sexes of the victim and perpetrator matter with who helps and who receives help (Latane and Dabbs 1975). In their nonemergency study, Latane and Dabbs (1975) found that females were more likely to receive help and males were more likely to give help. Further, with both sexes, there was a significant occurrence of diffusion of responsibility as the number of bystanders increased (Latane and Dabbs 1975).

\section{Seriousness of the Situation}

Previous literature has discussed the possibility of an event's severity of overriding the bystander effect, and there has been some support for this proposition. Fischer et al. (2006) found a significant bystander effect in non-dangerous situations, but 
in dangerous situations, there was no inhibiting effect caused by additional bystanders. For example, a rape in a parking lot received more help when there were more bystanders than just one (Harari et al. 1985). Furthermore, Nicksa (2014) found that serious and obvious damage to the victim, for example a physical assault, elicits higher intervention rates than instances where physical damage is not high, for instance a theft (Nicksa 2014). However, if the event is damaging to the victim but ambiguous, such as in cases of sexual assault, intervention rates may decrease. Lastly, bystanders are less likely to intervene in a situation when it requires medical care (Nicksa 2014). Banyard's (2008) study shows a result that is on the contrary with seriousness found by the above studies. The majority of participants $(85.1 \%)$ were more likely to ask a friend if they needed help when they seem upset (non-serious); however, the more serious scenario of walking a drunk friend home only received a concurring response of less than half, $41.2 \%$ (Banyard 2008).

A number of explanations have been proposed to explain these results. For instance, emergency situations are easier to recognize and are not as ambiguous as nonemergencies, which affects the costs of not intervening (Fischer et al. 2006). This explanation aligns with the assumptions of the arousal: cost - reward model, which states that emergency situations are unambiguous and severe, which will increase arousal that may be mitigated by intervening (Dovidio, Piliavin, Gaertner, Schroeder, and Clark 1991; Dovidio, Piliavin, Schroeder, and Penner 2006; Piliavin, Dovidio, Gaertner, and Clark 1981; Schroeder, Penner, Dovidio, and Piliavin 1995). According to Schwartz and Gottlieb (1976), dangerous emergency situations nullify individuals' concerns with 
evaluation apprehension (i.e., the anxiety of receiving negative evaluations from others) thereby increasing the likelihood of intervention.

Two other explanations draw from rational choice and information perspectives. Beginning with the former, the perceived cost of helping, likelihood of others helping, and the benefit to the victim contributes to the bystander's (in)action (Frazen 1999; Krueger, and Massey 2009; Penner, Dovidio, Piliavin, and Schroeder 2005). High costs for intervening should reduce intervention rates (Fischer et al. 2011). However, the dangerousness of some emergency situations may require more than one bystander for intervention to be successful, which may lead to an expectation for multiple bystanders to intervene (Fischer et al. 2011). Additional bystanders may reduce the bystander effect in emergency situations because they are seen as physical support. A bystander intervening in an emergency situation may have reason to believe they will come to physical harm, but the presence of additional bystanders may serve to mitigate that concern (Fischer et al. 2011). More bystanders may also lead to the situation being more likely and more quickly defined as an emergency, which would reduce the bystander effect (Fischer et al. 2011).

Victim-Offender Relationships

The victim-offender relationship holds extreme influence on bystander behavior and other outcomes (e.g., legal). For example, criminal sentencing research finds that African Americans who murder white individuals receive the death sentence more often than a white individual who murders an African American (Baldus, Woodworth and Pulaski 1990; Holcomb, Williams and Demuth 2004). Additionally, the clearance rates of homicides are affected by the victim-offender racial dyad. Roberts and Lyons (2009) 
found that non-white offenders are more likely to be cleared by arrest than white offenders. More specifically a nonwhite offender and white victim in a homicide had a clearance rate of $70 \%$ whereas a white offender and nonwhite victim had a clearance rate of 64\% (Roberts and Lyons 2009). A series of studies involving bystander intervention also illustrate how the characteristics of the victim-offender dyad affect prosocial behavior.

Family ties between the victim and perpetrator have been shown to influence bystander behavior (Shotland and Straw 1976; Levine 1999). Levine (1999) examined the murder case of James Bulger and discovered that bystanders did not act because they believed, or were told, that the three young boys were brothers. The bystanders' belief that the three boys shared a social category of being from the same family deflected intervention, which shows that the social meaning of groups contributes to the bystander effect (Levine 1999). Levine (1999) surmises that it may be a privatized view of the family that inhibited bystander intervention because of an insular perspective on children who do not belong to their family.

These same effects hold true among married individuals. Shotland and Straw (1976) specifically studied intervention rates when a male and a female are fighting. This study used two versions of the fight: (1) the two were a married couple and (2) they were strangers. Even though the fights were identical, respondents frequently found the fight between the strangers as more damaging, saw the female as asking for help more often, and intervened more than with the married couple. The fight between the married couple seems logical because these individuals have a closer relationship than the strangers in the second scenario (Shotland and Straw 1976). 


\section{Individual Factors}

Individual factors have been shown to be as inhibiting or encouraging as situational factors on bystander intervention. Snyder and Ickes (1985) suggest it is not only the environments that significantly affect bystander intervention but also the individual's characteristics, perceptions, and interpretations. Cognitive variables such as reasoning, self-concept, memory processes, values, self-efficacy, and perceptions have been linked to prosocial tendencies (Carlo and Randall 2001). Moral reasoning has also shown to significantly affect prosocial behavior (Underwood and Moore 1982). Further, task-skills, for example, understanding of time, are associated with certain kinds of prosocial behavior (Knight, Johnson, Carlo, and Eisenberg 1994; Knight, Bohlmeyer, Schneider, and Harris 1993). Research has also found that individuals who perceived themselves as more aggressive, stronger, and more sympathetic than others are more likely to intervene (Laner et al. 2001). These results suggest that the individuals who are most likely to intervene are ones who see themselves as physically capable of succeeding.

Christy and Voigt's (1994) results show that there is an effect on intervention when the bystander knows the perpetrator in some capacity. A bystander is more likely to forestall acts of child abuse if they are "emotionally invested in what acquaintances, friends, and relatives do, and are not passive when it comes to attempting to change the behavior of those they know" (Christy and Voigt 1994: 842). These findings follow the same result when considering the bystander's relationship to the victim. If the victim is known or if the bystander expects future contact with them, help is more likely to be given (Christy and Voigt 1994). 
These individual factors attempt to capture an overarching view of how an individual's perceptions may drastically affect their intervention. However, a closer look at these individual bystanders is required to fully understand individual factors. One factor that may be highly influential could be the bystander's biases that they hold toward those involved in the helping situation.

\section{Stigmatization's Influence}

Bystanders become more aware, by heightened sensitivity, to the cost of helping when the individual in need of assistance is stigmatized (Ungar 1979). Literature exploring help received by physically stigmatized individuals has discovered two opposing bystander behaviors: increased empathy that increases helping and reduced attractiveness that reduces helping and increases discomfort (Ungar 1979). Ungar (1979) found that in low effort, non-emergency situations there was not a significant difference in bystander intervention when the situation involved a nonstigmatized versus a stigmatized victim (e.g. wore an eye patch). However, Ungar (1979) found that in high effort situations, when an observer had to give an immediate response, stigmatized victims were less likely to be helped. Ungar (1979) hypothesized that for the bystander to not provide assistance to a stigmatized victim they must justify their inaction; "the victim's circumstances are attributed to something the victim did or failed to do, thereby reducing the person's responsibility for not helping” (Ungar 1979:28).

Levine, Cassidy and Brazier (2002) discovered that bystanders are more likely to help victims who are described as in-group members as opposed to those from an outgroup. However, increased levels of contact with out-group members (i.e., intergroup contact) have been shown to indirectly affect group helping behaviors (Abbott and 
Cameron 2014). Specifically, higher levels of intergroup contact are significantly associated with higher levels of empathy, which lead to more assertive helping behaviors (Abbott and Cameron 2014). Additionally, as intergroup contact increases so do levels of cultural openness, which again results in more helping behaviors. Further, intergroup contact lowers in-group bias, which in turn increases the intention to intervene. In sum, more intergroup contact is associated with higher levels of empathy and cultural openness and lower levels of intergroup bias, which generates a greater likelihood of helping behavior (Abbott and Cameron 2014).

\section{EXamining The Role OF Sexual ORIENTation ON Prosocial Behavior}

This research explores an understudied individual-level factor that may affect prosocial behavior - sexual orientation. Ryan and Wessel (2012) examined sexual orientation harassment in the workplace, and when or if bystanders intervene. These researchers examined how perceived harm, directness of harassment, knowledge of orientation, relationship to target, and recurrence beliefs affected bystander intervention. Also, if the decision to intervene was achieved, they examined how cost and benefits and recurrence beliefs affect their level of involvement and immediacy of involvement.

In their two studies, Ryan and Wessel (2012) find significantly increased intervention rates when the harassment is clearly a direct insult to the victim. The researchers used an online questionnaire for study one that asked the participants about an event of sexual orientation harassment in the workplace. In study two, participants were given a scenario of sexual orientation harassment in the workplace to determine their perceptions. Results show that when the victim's sexual orientation is not known intervention on homophobic harassment decreases, opposed to when sexual orientation is 
known. This may be because the observer does not see the remark as an insult because they do not know the receivers' sexual orientation. The relationship (e.g., did not know, knew casually, fairly good acquaintance, and good friend) to the target was significant in the first study but not the second. This may have been caused by study one using real relationships and study two using hypothetical relationships. This research provides a glimpse of the process behind sexual orientation harassment, and underscores the importance for a closer empirical exploration, "We know little about when and why observers choose to intervene..."(Ryan and Wessel 2012: 506).

The prediction accuracy of the bystander effect when considering a bias held by the would-be intervener is one of the less explored variables. Ungar (1979) found that bystanders do not help stigmatized individuals as much as the nonstigmatized. In the case of this project, it is believed that a homophobic person would stigmatize homosexuality, which may replicate what Ungar (1979) found. I hypothesize that the bystander effect's strength will diminish when controlling for the bystander's bias. Specifically, the bystander's likelihood of intervening will be more so influenced by their bias than by the number of bystanders. Also, I hypothesize, that homophobic individuals will be less likely to help a homosexual victim than a heterosexual victim. This is believed because of the influence stigma has on bystander behavior.

As previously shown, bystander intervention has been analyzed with several different viewpoints looking at social, individualistic and situational factors and how they affect bystander intervention. However, with this plethora of empirical research and theoretical understanding, there are areas that have not been explicitly explored. 
Specifically, previous research has largely ignored internal biases held by the bystander, and how they affect their (in)action.

Using the Attitudes Toward Lesbians and Gay Men Scale, Lyons (2006) measured possible anti-gay prejudice in the sample. His study explored how the sample placed blame on the victims of a physical assault that happened because of an instance of public display of affection (PDA). The higher a participant's score on the ATLG scale the more homophobic the individual is considered. Individuals who scored high on the scale attributed more blame to both homosexual and heterosexual victims for being victims of a physical assault than individuals who scored low (Lyons 2006). However, there is a much greater effect of the attitudes with blaming homosexual victims than heterosexual victims (See Figure 2). Further, the majority of the participants ignored PDA by the heterosexual victims, but not the homosexual couples (Lyons 2006). It seems that homosexual couples are subjected to a double standard that their PDA is blameworthy because of it being against societal norms (Lyons 2006). 


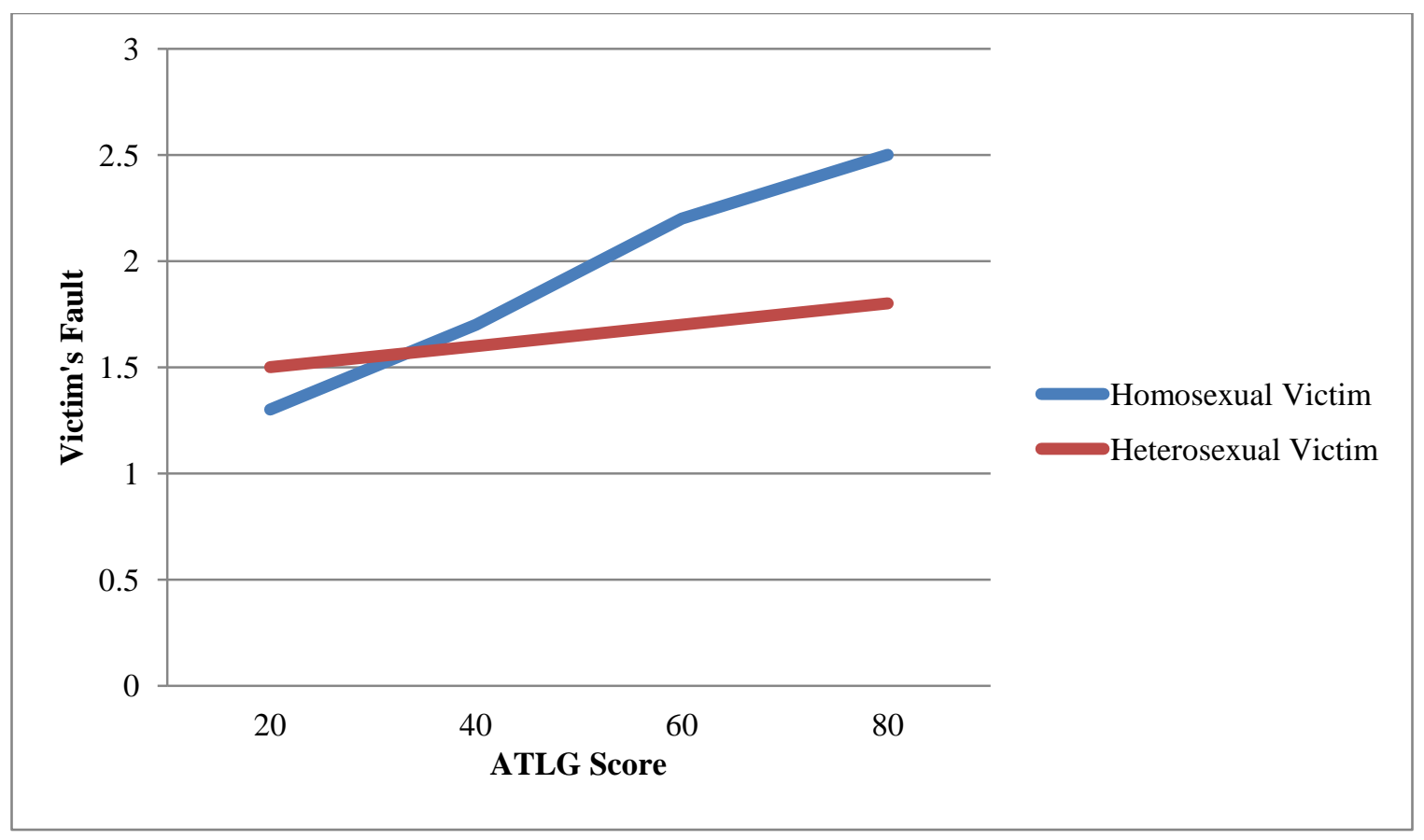

Figure 2. Effect of Attitudes Toward Lesbians and Gays on Attributions of Victim's Fault by Victim Sexual Orientation. (Lyons 2006: 50)

\section{Research Objectives}

The purpose of this research is to examine how much influence homophobic biases have bystander intervention rates when homosexuals are involved in a physical altercation. The attitudes towards homosexuals are analyzed closely while also looking for relationships among other variables and intervention likelihood: sex, sexual orientation, social desirability, and bystander group size. These answers will contribute to the considerable gap in the literature regarding the role of biases on intervention, and have the opportunity to add more understanding to bystander behavior by supporting or refuting previous research. This study poses three research questions: (1) Does the bystander effect accurately predict bystander intervention in fights when bias is controlled for?; (2) Are homophobic individuals less likely to intervene in a physical fight with a homosexual victim?; (3) Is the strength of bias consistent across conditions? 
Knowing exactly how this individualistic variable affects each bystander differently may lay a new foundation to another branch of the bystander effect or new theoretical understanding.

\section{DATA AND METHODS}

This study uses a quasi-experimental factorial vignette design (Rossi and Nock 1982). This research method is advantageous because it allows the researcher to manipulate multiple variables across the vignettes, many of which cannot be realistically manipulated in a laboratory. The sample was collected through convenience sampling in introductory college courses at a large land-grant university in Appalachia. Having this kind of sample may inhibit the generalization of the results to other populations. However, Steffenmeier and Kramer (1982) found that vignette results studying criminological phenomena do generalize from college student populations to general citizens. Furthermore, Nuñez et al. (2011) suggest that any differences between convenient, student samples and the general population may be modest at best.

\section{Participants}

Vignettes were randomly assigned to 938 undergraduate students. After close review, 127 observations were removed from the sample for incompleteness or obvious patterns in answer choices, yielding a final total of 811 observations. The vignettes describe a physical fight between two males that occurs outside a bar. Respondents answered questions about their perceptions of intervention likelihood, questions that measure social desirability and their attitudes toward homosexuals, and demographic questions. The survey took approximately 10 to 15 minutes to complete. 
Of the sample respondents, $54 \%$ were female, $89 \%$ heterosexual, and $83 \%$ white. The mean age was 19.6 years. With regard to major, $30 \%$ were social science majors, $20 \%$ natural/physical science, $14 \%$ were business, $11 \%$ were humanities, $10 \%$ were other, $8 \%$ were engineering or computer science, $4 \%$ were undecided, and $3 \%$ were education. Of the sample, 32\% identified as Independent, 25\% Democrat, and 31\% Republican. Also, 67\% stated they were Christian.

\section{Experimental Design}

I conducted a $2 \times 5$ vignette experiment that varies on bystander group size (alone vs. with 10 others) and the perpetrator/victim's sexual orientation (no sexual orientation mentioned, heterosexual/homosexual, homosexual/heterosexual, heterosexual/heterosexual, homosexual/homosexual). The data from the control vignettes (no sexual orientation is mentioned) allows for a baseline measurement of intervention rates and the bystander effect in general physical altercation settings. These rates can be directly compared to the vignettes that mention sexual orientation to discover differences in intervention rates. I manipulate all sexual orientation combinations for instrumental completeness. In all vignettes, the perpetrator and victim are white, males, and of average height ( $\left.5^{\prime} 11\right)$ and weight (170 pounds). See Figure 3 for experimental design. 


\begin{tabular}{|c|c|c|c|c|c|c|}
\hline \multirow{4}{*}{$\begin{array}{c}\text { Bystander } \\
\text { Status }\end{array}$} & \multirow[b]{3}{*}{ Alone } & \multicolumn{5}{|c|}{ Perpetrator/Victim Sexual Orientation } \\
\hline & & $\begin{array}{l}\text { No Sexual } \\
\text { Orientation }\end{array}$ & $\mathrm{He} / \mathrm{Ho}$ & $\mathrm{Ho} / \mathrm{He}$ & $\mathrm{He} / \mathrm{He}$ & $\mathrm{Ho} / \mathrm{Ho}$ \\
\hline & & Condition 1 & Condition 3 & Condition 4 & Condition 7 & Condition 8 \\
\hline & $\begin{array}{l}\text { With } 10 \\
\text { Others }\end{array}$ & Condition 2 & Condition 6 & Condition 5 & Condition 9 & Condition 10 \\
\hline
\end{tabular}

Notes: "He" denotes "heterosexual," and "Ho" denotes "homosexual." The perpetrator is always listed first.

\section{Figure 3. Experimental Design}




\section{Stimuli}

The vignettes describe a setting of walking home after going to a bar and seeing a physical fight. First, one male yells a non-status insult at the other. Next, the male who yelled the insult initiates a physical fight once the other male starts to walk away. To manipulate the vignettes based on bystander group size, there are five scenarios where the participant witnesses the incident alone and five where they are with ten other bystanders who are strangers. Sex, race, height, and weight of the victim and perpetrator are held constant; all are 5'11, 170 pounds, white males. A copy of the vignette used in Condition 4 is listed in Appendix A.

\section{Variables and Measurements}

\section{Dependent Variables}

There are three dependent variables for this study - general intervention, physical intervention, and verbal intervention. These were measured using three questions on a 10point scale of strongly disagree (1) and strongly agree (10).

- I will try to stop the fight.

- I will try to stop the fight physically.

- I will try to stop verbally.

\section{Independent Variable}

The main independent variable is the participant's Attitudes Toward Lesbians and Gay Men (ATLG) score (Herek 1988). ${ }^{2}$ There are 10 questions, and the scores range from 10 , an extremely positive attitude towards homosexuals, to 100 , an extremely

\footnotetext{
2 The ATLG scale used was the revised short version \#1 consisting of 10 questions (Herek 1994). This version was used for its conciseness and limited time needed for participates to complete the questions. Also, this scale has shown to be internally consistent with the larger version (Herek 1988).
} 
negative attitude towards homosexuals. Five questions ask about homosexuality in males and five ask about homosexuality in females. This construction allows for the creation of three variables: (1) total attitudes towards homosexuals, (2) attitudes towards gay men, and (3) attitudes towards lesbians.

Costa, Banderia, and Nardi (2013) completed a systematic review of instruments measuring homophobia. Of the 47 scales analyzed, the ATLG scale was ranked second. However, the reasoning for choosing this scale over the first, Index of Attitudes Toward Homosexuals/Index of Homophobia (IATH), is because the ATLG scale allows for direct comparisons between an individual's attitudes towards lesbian and gay men. Further, the ATLG scale has been used in several different cultures, such as Ireland, Chile, and The Netherlands, several occupations ranging from college student to healthcare professional, and with a military sample (Costa et al. 2013). Also, the IATH has been criticized for appealing to Wienberg's ideas and only examining "the affective facet of the construct of homophobia" (Costa et al. 2013:1329).

\section{Control Variables}

Four major variables will be controlled for: social desirability scores (SDS) (Crowne and Marlowe 1960), participant sexual orientation, and sex. It is expected that as the social desirability of a participant increases, the intervention likelihood will increase, but I do not know of previous research that has explored this variable with intervention. The SDS uses 10 questions on a true/false basis; however, for this study, the questions were put on a 10-point scale. ${ }^{3}$ This was done to show more variability in scores. Scores can fall from 10 to 100 . The higher the score, the more socially desirable actions the

\footnotetext{
${ }^{3}$ The SDS used was the short 10-question X1 Form (Fischer and Fick 1993).
} 
person stated they would commit. Strahan and Gerbasi's (1972) study supports the reliability of the two short versions with X1 being slightly superior. Further, Fischer and Fick (1993) confirm these findings concluding that the X1 Form has high internal consistency and is significantly correlated with the original scale.

The sexual orientation of the participant will be controlled for because of the lack of research that controls for this variable. Also, previous research has shown perceived in-group/out-group status of the victim and bystanders has significant influence on intervention likelihood (Levine et al. 2002). This study explores if this sample supports previous results.

Finally, I control for sex. Research completed by Herek (1988) shows distinct patterns among males and females where males hold a more negative view towards gay men than lesbian. However, female's views are consistent with gay men and lesbians. However, I am controlling for sex to see the differences of helping behavior between males and females. This analysis will reexamine this finding and further explore if these negative attitudes' influence (in)action.

\section{Pre-Testing of Instrument}

Two pilot studies were completed for this project. First, six interviews were conducted to test the clarity and consistency of the vignettes. The interviews lasted approximately 20 minutes each and were recorded for transcription after permission was obtained. There were three questions asked that pertain to the vignettes: (1) What race or races did you imagine the two males being?; (2) Were there any weapons present in the fight?; (3) Who is to blame for starting the fight? 
I wanted to be sure the participants were all imagining the physical fights as similarly as possible. The participants did accurately choose the true perpetrator - based off of fight initiation - in each vignette, and were confident about the absence of weapons. However, participants were not consistent with the race of the two males. To mitigate this inconsistency, race was explicitly stated in the final version of the vignettes. Also, from the race question, another issue was brought to light. It was apparent that participants consistently thought of the perpetrator as larger, in regards to height and weight, than the victim. To make this aspect of the vignette consistent, I explicitly state the height and weight of each male.

The second pilot test was a test of the instrument. In this pre-test I used six of the ten vignettes. The vignettes that were excluded were the ones where the perpetrator and victim had the same sexual orientations. During a sociology course at a large land-grant university in Appalachia, 47 students completed the surveys. After removing surveys for incompleteness and visible patterns, 43 observations remained. For the purposes of this pre-test, only a select few variables are analyzed: bystander status, the dyad's sexual orientation, the three intervention types, and ATLG scores.

The objective of the pre-test was to explore how long it took participants to complete the instrument, and to test for interdependence between the conditions and the two scales: ATLG and SDS. An average completion time was obtained to better plan the larger data collection date, and tests on interdependence were insignificant, meaning participants were not responding to the scales in a certain way based on the vignette condition they were randomly assigned. 


\section{RESULTS}

To make interpretation of the 10 conditions easier, I have created a key to address which condition is being reported. The dyad will always be reported as perpetrator/victim. "Con" will always denote the control condition (i.e., no sexual orientation mentioned), "He" will always denote heterosexual, "Ho" will always denote homosexual, " $\mathrm{A}$ " will always denote that participant is alone, and " 10 " will always denote the participant is with 10 other strangers. For example, if the condition has a heterosexual perpetrator, homosexual victim and the participant is alone the key will be "He/Ho/A."

Three sets of regression analyses were performed to explore my research questions. First, I regressed participant's intervention - general, physical, and verbal - on their experimental condition, controlling for SDS and participant sex. The goal of this analysis is to determine whether or not the dyadic relationship between the offender and victim affects helping behaviors and whether such intervention is subject to the bystander effect. These results are listed in Table 1 . The second set of regression analyses chooses only those conditions $(\mathrm{He} / \mathrm{Ho} / \mathrm{A}, \mathrm{He} / \mathrm{Ho} / 10, \mathrm{Ho} / \mathrm{He} / \mathrm{A}, \mathrm{Ho} / \mathrm{He} / 10)$ that include differing sexual orientations of the perpetrator and victim. Here, the goal is to determine whether individual homophobic biases, as measured by the ATLG scale, influence helping behaviors when the dyad's sexual orientations differ. I again control for SDS and participant sex but also control for participant's sexual orientation. These results are presented in Table 2.

The third and final analysis completed in this study is to explore the strength of ATLG scores and controlling variables across the four conditions where the sexual 
orientation of the perpetrator and victim differ. To complete this analysis, twelve regressions were used to explore each dependent variable in each condition by the type of intervention. The controlling variables for these regressions are the participant's sex, SDS, and sexual orientation. The results for these regressions are in Table 3.

\section{Analysis 1: Effect of Perpetrator/Victim Dyad on Bystander Intervention}

Model 1 in Table 1 reveals two conditions that significantly affect general intervention compared to the reference group (i.e., Con/A: no mention of offender/victim dyad sexual orientation and no bystanders). Specifically, participants in $\mathrm{He} / \mathrm{Ho} / \mathrm{A}\left(t^{*}=\right.$ $2.06, p=.039)$ and $\mathrm{He} / \mathrm{Ho} / 10\left(t^{*}=2.18, p=.028\right)$ are significantly more likely to intervene as compared to those in the reference group. Models 2 and 3 do not yield any significant experimental conditions, at least as compared to the reference group. 
Table 1. OLS Regression Results by Intervention Type for All Vignette Conditions

\begin{tabular}{|c|c|c|c|}
\hline & Model 1 & Model 2 & Model 3 \\
\hline $\begin{array}{c}\text { Dependent } \\
\text { Variables }\end{array}$ & General Intervention & $\begin{array}{c}\text { Physical } \\
\text { Intervention }\end{array}$ & Verbal_Intervention \\
\hline $\begin{array}{l}\text { Experimental } \\
\text { Condition: } \\
\text { (1) Con/A }\end{array}$ & & Reference Group & \\
\hline (2) Con/10 & $.030(.450)$ & $-.062(.369)$ & $-.245(.439)$ \\
\hline (3) $\mathrm{He} / \mathrm{Ho} / \mathrm{A}$ & $.920(.446)^{* *}$ & $.481(.382)$ & $.718(.441)$ \\
\hline (4) $\mathrm{Ho} / \mathrm{He} / \mathrm{A}$ & $.389(.465)$ & $.430(.445)$ & $.662(.445)$ \\
\hline (5) $\mathrm{Ho} / \mathrm{He} / 10$ & $.551(.463)$ & $-.239(.407)$ & $.476(.449)$ \\
\hline (6) $\mathrm{He} / \mathrm{Ho} / 10$ & $.959(.439)^{* *}$ & $.408(.396)$ & $.611(.448)$ \\
\hline (7) $\mathrm{He} / \mathrm{He} / \mathrm{A}$ & $-.379(.448)$ & $-.441(.388)$ & $-.237(.438)$ \\
\hline (8) $\mathrm{Ho} / \mathrm{Ho} / \mathrm{A}$ & $.027(.475)$ & $.164(.396)$ & $-.189(.452)$ \\
\hline (9) $\mathrm{He} / \mathrm{He} / 10$ & $-.623(.472)$ & $-.581(.381)$ & $-.510(.448)$ \\
\hline (10) $\mathrm{Ho} / \mathrm{Ho} / 10$ & $.071(.464)$ & $.050(.422)$ & $-.023(.433)$ \\
\hline \multicolumn{4}{|c|}{ Control Variables: } \\
\hline Male & $.634(.203)^{* * *}$ & $2.44(.179)^{* * *}$ & $-.243(.199)$ \\
\hline $\mathrm{SDS}$ & $.032(.009)^{* * *}$ & $.007(.007)$ & $.036(.009)^{* * *}$ \\
\hline Constant & $3.158(.642)^{* * *}$ & $1.952(.561)^{* * *}$ & $3.840(.654)^{* * *}$ \\
\hline $\begin{array}{l}\text { Summary } \\
\text { Statistics: } \\
\text { Adj. } R^{2}\end{array}$ & .044 & .215 & .035 \\
\hline$N$ & 787 & 787 & 787 \\
\hline
\end{tabular}

Notes: Robust standard errors in parentheses. The reference group for all models is Con/A (the dyad condition where no reference to offender/victim sexual orientation is made and the participant witnesses the event alone).

$* p<.10 ; * * p<.05 ; * * * p<.01$ (two-tailed tests).

To further explore any significant differences in intervention between experimental conditions, I ran post-hoc tests to determine if any other conditions were significantly different from each other, and not just the initial reference group. Figure 4, Panels A-C, show the overall intervention rates by type for each model in Table $1-$ general, physical, and verbal, respectively. In Panel A, He/Ho/A, He/Ho/10, $\mathrm{Ho} / \mathrm{He} / \mathrm{A}$, and $\mathrm{Ho} / \mathrm{He} / 10$ are significantly different than all other groups. Significant conditions from Figure 4, Panel A show higher general intervention rates than the other six 
conditions. Panel B does not yield any groups that are significantly different. Panel C shows significant differences with $\mathrm{Con} / \mathrm{A}, \mathrm{He} / \mathrm{Ho} / \mathrm{A}, \mathrm{He} / \mathrm{Ho} / 10, \mathrm{Ho} / \mathrm{He} / \mathrm{A}$, and $\mathrm{Ho} / \mathrm{He} / 10$ with all other conditions. Significant conditions from Figure 4, Panel C show higher verbal intervention than the other five conditions. 
Panel A. General Intervention by Condition

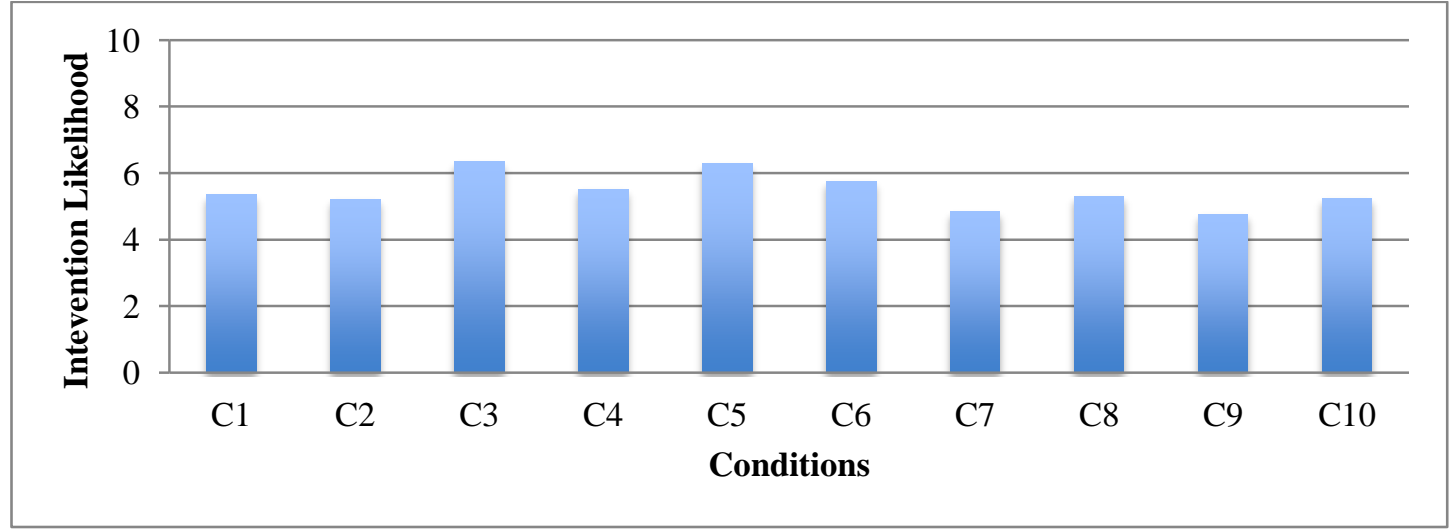

Panel B. Physical Intervention by Condition

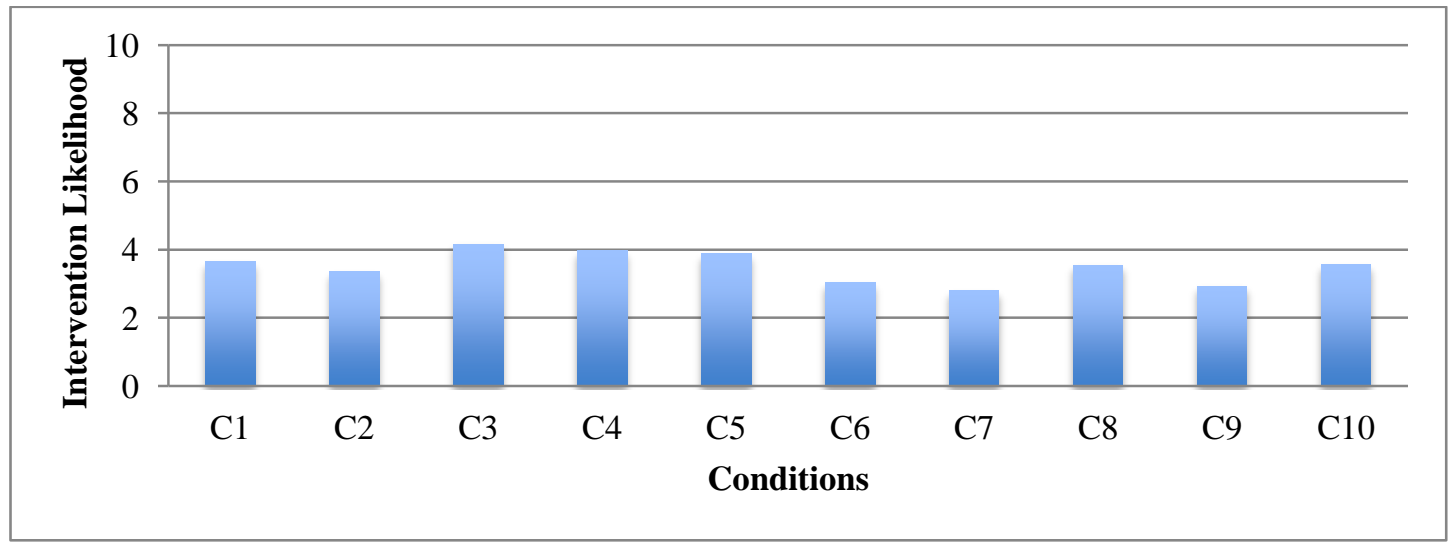

Panel C. Verbal Intervention by Condition

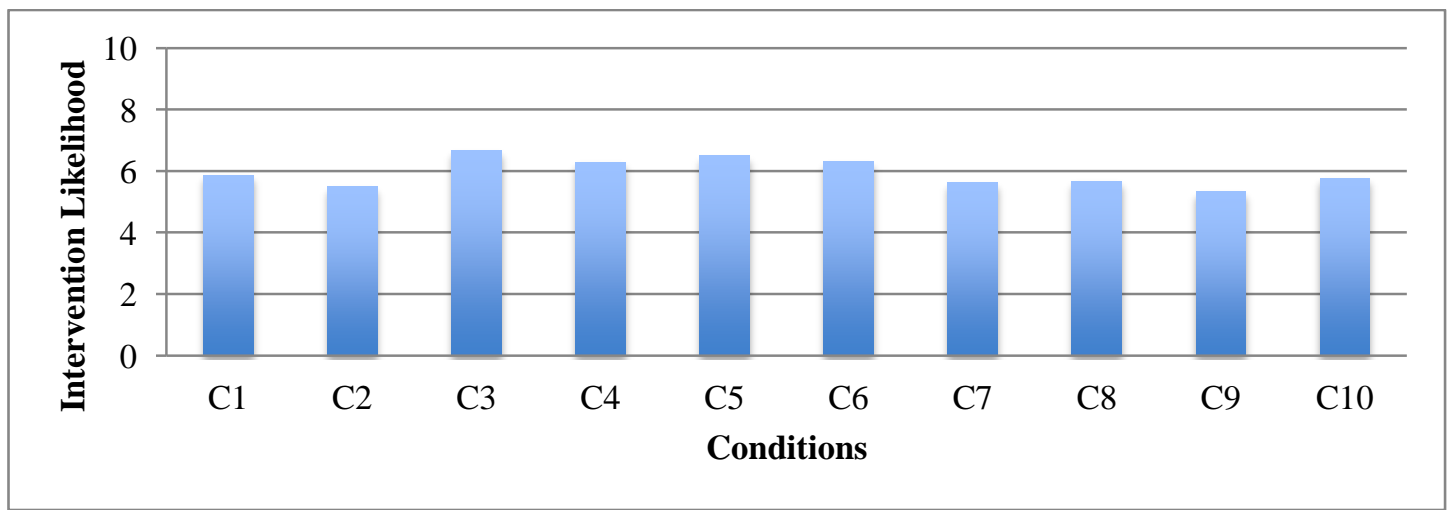

Notes: The condition numbers in Figure 4, Panels A, B, and C match the condition numbers in Table 1.

Figure 4. Overall Intervention Rates for Regression Table 1 
The control variables in Models 1-3 - participant's sex and social desirability score - vary in significance. With regard to both general $\left(t^{*}=3.12, p=.002\right)$ (Model 1) and physical intervention $\left(t^{*}=13.60, p<.0001\right)$ (Model 2), males are more likely to intervene than females. However, participant sex does not affect the likelihood of verbal intervention (Model 3). Also, as a participant's social desirability score increases, their likelihood of both general intervention (Model 1: $t^{*}=3.52, p<.0001$ ) and verbal intervention (Model 3: $\left.t^{*}=3.90, p<.0001\right)$ increase.

\section{Analysis 1: Discussion and Implications}

The first three regressions included all ten conditions and controlled for the participant's sex and SDS score. These regressions allow for a closer look at the bystander effect's power on this sample. Results show that there are higher general intervention rates in conditions $\mathrm{He} / \mathrm{Ho} / \mathrm{A}$ and $\mathrm{He} / \mathrm{Ho} / 10$ than $\mathrm{Con} / \mathrm{A}$. This shows the positive effect of knowing the sexual orientations of the perpetrator and victim on intervention. This information may lessen the ambiguity of the event, and that would increase intervention, which supports previous literature (Fischer, Greitemeyer, Kastenmuller, Krueger, Vogrincic, Frey, Heene, Wicher, and Kainbacher 2011; Nicksa 2014). This also shows that, perhaps, the bystander effect is not at full strength when sexual orientation is known. This statement is supported by previous literature that found when sexual orientation is known intervention increases (Ryan and Wessel 2012). Further, knowing the sexual orientations may create another situation where having more observers increases intervention, which has been found in specific situations (Harari et al. 1985; Schwartz and Gottlieb 1976). This knowledge may be increasing intervention 
because of evaluation apprehension; the participants do not want to be evaluated as homophobic or supportive of an attack on a gay male.

The effect of knowing the sexual orientations of the perpetrator and victim start to lay the foundation of the social milieu around this topic in present day. Sexual orientation receives high levels of media coverage, some of which is because of gay marriage being legalized in $2015^{4}$ and to some because of LGBT youth committing suicide ${ }^{5}$ as a result of being bullied. These events make sexual orientation less of an alien concept to the populace, which may be causing higher intervention rates when the heterosexual male is attacking the homosexual male.

Figure 4, Panel A and Panel C, shows the differences in overall intervention rates by condition for Table 1 . Panel A shows a significantly higher general intervention rates between conditions $\mathrm{He} / \mathrm{Ho} / \mathrm{A}, \mathrm{Ho} / \mathrm{He} / \mathrm{A}, \mathrm{He} / \mathrm{Ho} / 10$, and $\mathrm{Ho} / \mathrm{He} / 10$ and all other conditions. This significant finding furthers the previous result of the influence of knowing the sexual orientations. However, Panel A takes this finding further. Panel A's significant groups comparison test not only shows how knowing sexual orientation is influential to bystander intervention, but also confirms higher level of intervention when the sexual orientation of the perpetrator and victim differ. The differing of perpetrator/victim sexual orientations seems to show a power imbalance that facilitates more arousal among the participants, which, in turn, increases their intervention. Also, this power imbalance may cause the event to be seen as more severe, which previous literature has found to increase intervention (Fischer et al. 2006; Nicksa 2014).

\footnotetext{
${ }^{4}$ See Obergefell v. Hodges (2015)

${ }^{5}$ For a few examples of these suicides see Anon. (n.d.), Parker (2012), The Globe and Mail (2012), and The Huffington Post (2013).
} 
Figure 4, Panel $\mathrm{C}$ shows the overall verbal intervention rates for Table 1. This result shows conditions $\mathrm{He} / \mathrm{Ho} / \mathrm{A}, \mathrm{Ho} / \mathrm{He} / \mathrm{A}, \mathrm{He} / \mathrm{Ho} / 10$, and $\mathrm{Ho} / \mathrm{He} / 10$ are significantly different than all other conditions for verbal intervention. This finding echoes Panel A's finding on general intervention. Panel A and Panel C explicitly show differing sexual orientations are causing statistically higher general and verbal intervention, respectively, when sexual orientation is known than when the sexual orientations are the same or unknown. These results highlight the need to further explore individualistic characteristics of bystanders to create a more complete understanding of prosocial behaviors.

\section{Controlling Variables}

The first three regressions controlled for the participant's sex and SDS. From the first three regressions, in reference to cost and risk, males are - generally and physically - more likely to intervene than females. This finding is supported by previous research that males intervene more in situations that may be dangerous (Piliavin, Allyn, and Charng 1990).

There is a significant effect of the participant's social desirability score on intervention. Participants who answer the SDS questions in a more socially desirable way show a significant increase in general and verbal intervention in all regressions. This may support Ungar's (1979) premise that a stigmatized individual being involved - the homosexual - causes participants to be more aware of the situation, which, in turn, may increase action. However, I am not aware of any current research analyzing the effect of social desirability on prosocial behaviors. This result is one that was expected; however, 
SDS is an understudied variable with helping behavior. This result highlights the need for further examination.

\section{Analysis 2: Effect of Individual Biases on Bystander Intervention}

The second set of three regression models are shown in Table 2. These models analyze the effect of the participant's ATLG score, sex, social desirability score, and sexual orientation on the three types of intervention. The reference group for all three analyses is $\mathrm{He} / \mathrm{Ho} / \mathrm{A}$.

Focusing first on the role of homophobic bias on intervention likelihood, all three models report significant and negative relationships between ATLG score and general, verbal and physical intervention. Specifically, as the participant's ATLG score increases, which indicates more homophobic beliefs, their likelihood of intervening significantly decreases.

The only significant vignette condition is $\mathrm{Ho} / \mathrm{He} / 10$ in the physical intervention model (Model 2). Individuals in this condition were significantly less likely to intervene, compared to those in the reference condition $(\mathrm{He} / \mathrm{Ho} / \mathrm{A})\left(t^{*}=-1.98, p=.048\right)$. Post-hoc tests were completed to determine if any of the conditions in Table 2 are significantly different from each other, and not just the reference group. Figure 5, Panels A-C, show the overall intervention rates for general, physical, and verbal intervention. Panels A and $\mathrm{C}$ do not have any significant differences. In Panel B, condition Ho/He/10 has significantly lower physical intervention rates than the other three conditions. Figure 5, Panel B and Panel C show that our sample would intervene more so verbally than physically. 
Table 2. OLS Regression Results by Intervention Type for Only Differentiated Vignette Conditions

\begin{tabular}{|c|c|c|c|}
\hline & Model 1 & Model 2 & Model 3 \\
\hline $\begin{array}{l}\text { Dependent } \\
\text { Variables }\end{array}$ & General Intervention & $\begin{array}{c}\text { Physical } \\
\text { Intervention }\end{array}$ & Verbal Intervention \\
\hline $\begin{array}{l}\text { Independent } \\
\text { Variable: } \\
\text { ATLG Score }\end{array}$ & $-.038(.006) * * *$ & $-.012(.006)^{*}$ & $-.040(.006)^{* * * *}$ \\
\hline $\begin{array}{l}\text { Experimental } \\
\text { Conditions: } \\
\text { (3) } \mathrm{He} / \mathrm{Ho} / \mathrm{Alone} \\
\text { (4) } \mathrm{Ho} / \mathrm{He} / \mathrm{A} \\
\text { (5) } \mathrm{Ho} / \mathrm{He} / 10 \\
\text { (6) } \mathrm{He} / \mathrm{Ho} / 10\end{array}$ & $\begin{array}{l}-.191(.429) \\
-.427(.436) \\
.031(.398)\end{array}$ & $\begin{array}{c}\text { Reference Group } \\
.062(.414) \\
-.748^{* *}(.377) \\
-.062(.414)\end{array}$ & $\begin{array}{r}.130(.430) \\
-.363(.431) \\
-.097(.400)\end{array}$ \\
\hline $\begin{array}{l}\text { Controlling } \\
\text { Variables: } \\
\text { Male } \\
\text { SDS } \\
\text { Sexual Orientation }\end{array}$ & $\begin{array}{l}.597(.302)^{* *} \\
.054(.013)^{* * *} \\
.056(.547)\end{array}$ & $\begin{array}{c}2.672(.295)^{* * *} \\
.013(.012) \\
.324(.561)\end{array}$ & $\begin{array}{l}-.192(.303) \\
.030(.013)^{* *} \\
-.211(.545)\end{array}$ \\
\hline Constant & $4.129(1.00)^{* * *}$ & $2.108(1.00)^{* *}$ & $6.621(.996)^{* * *}$ \\
\hline $\begin{array}{l}\text { Summary } \\
\text { Statistics: } \\
\text { Adj. } \mathrm{R}^{2} \\
N\end{array}$ & $329^{.135}$ & $329^{.230}$ & $329^{.105}$ \\
\hline
\end{tabular}

Notes: Robust standard errors in parentheses. $\mathrm{N}=329$ for all models. The reference group for all models is Con/A (no reference to sexual orientation with the participant alone). * $\mathrm{p}<.10 ; * * \mathrm{p}<.05 ; * * * \mathrm{p}<.01$ (two-tailed tests). 
Panel A. General Intervention by Condition

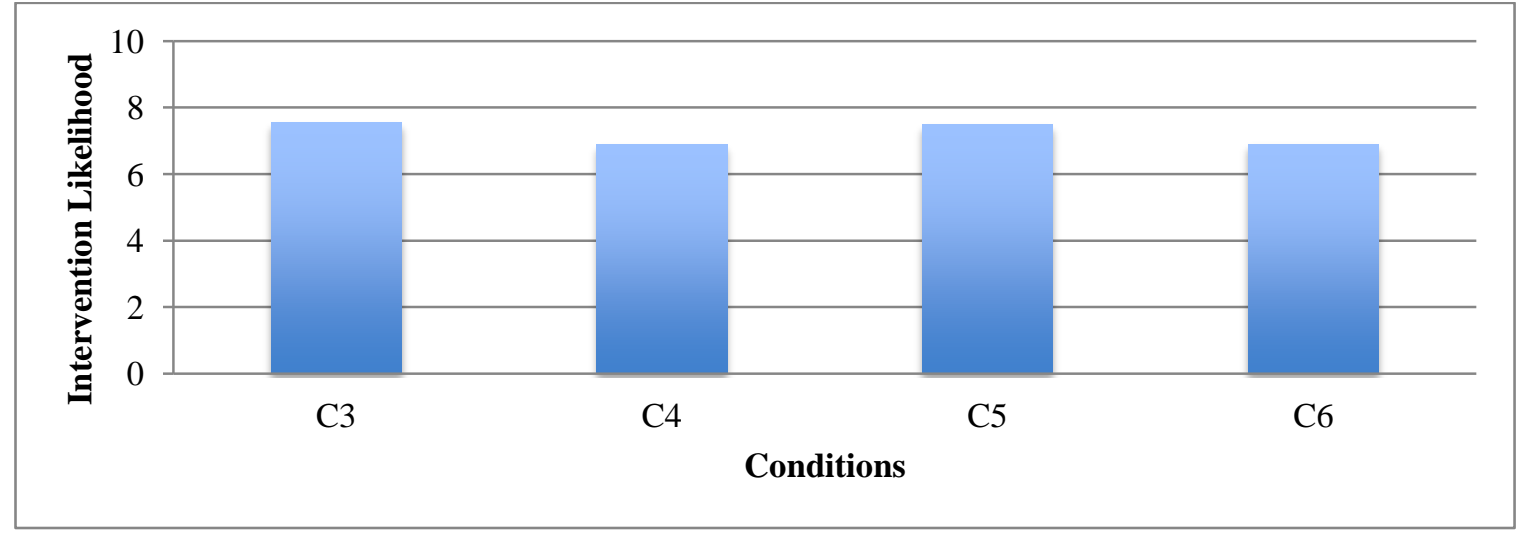

Panel B. Physical Intervention by Condition

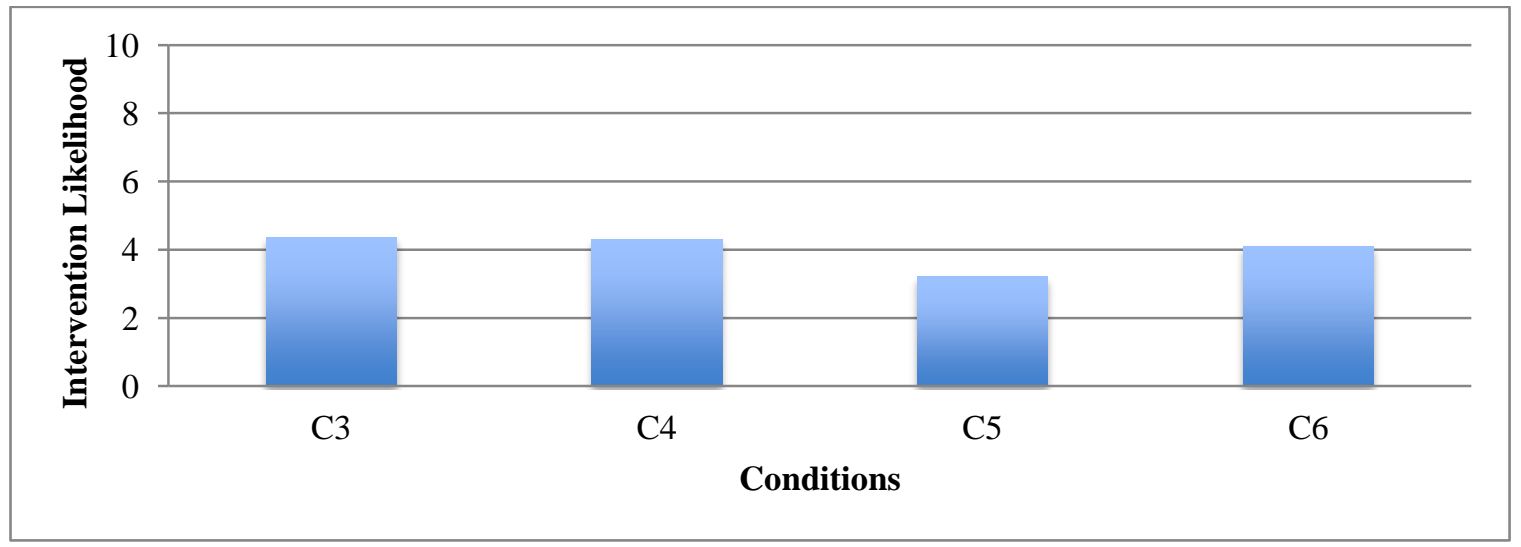

Panel C. Verbal Intervention by Condition

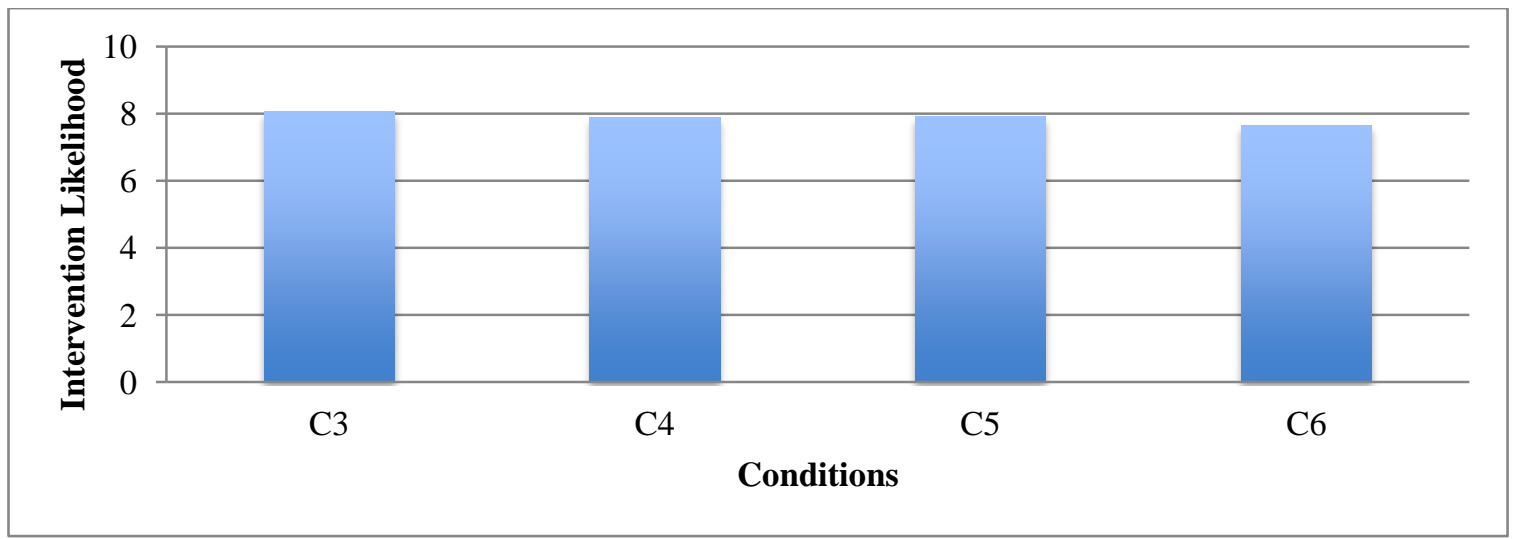

Notes: The condition numbers in Figure 4, Panels A, B, and C match the condition number in Table 1.

Figure 5. Overall Intervention Rates for Regression Table 2, Controlling for ATLG Scores, Sex, Social Desirability, and Participant's Sexual Orientation. 
The control variables for Table 2, Models 1-3 are sex, social desirability, and the participant's sexual orientation. The sex of the participant was only significant in Models 1, general intervention, $\left(t^{*}=1.97, p=.049\right)$, and 2 , physical intervention, $\left(t^{*}=9.04, p<\right.$ .0001). In both models, males were more likely to intervene than females. Participant social desirability scores have a significant positive effect on general $\left(t^{*}=4.18, p<.0001\right)$ and verbal $\left(t^{*}=2.27, \mathrm{p}=.024\right)$ intervention. The participant's sexual orientation was not significant in any Table 2 model.

\section{Analysis 2: Discussion and Implications}

The second set of regressions allows for direct analysis of the participant's ATLG score, sex, social desirability score, and sexual orientation. These three regressions include the four conditions where the sexual orientations of the perpetrator and victim differ $-\mathrm{He} / \mathrm{Ho} / \mathrm{A}, \mathrm{Ho} / \mathrm{He} / \mathrm{A}, \mathrm{Ho} / \mathrm{He} / 10$, and $\mathrm{He} / \mathrm{Ho} / 10$. The focus of this paper is to shed light on how attitudes toward lesbians and gay men can affect bystander behavior in an event that includes a homosexual, which is what this analysis aims to explain.

The results show there is a significant negative relationship with the participant's ATLG score and bystander intervention. As the participant's ATLG score increases, they are significantly less likely to intervene generally, physically, and verbally. Specifically, this means the more homophobic individuals were statistically less likely to intervene on behalf of a victim during a physical attack. This answers the questions of does a more homophobic individual performs less prosocial behaviors in this scenario. This does not directly support known past research; however, it does align with related research ${ }^{6}$. The ATLG score negatively affecting intervention as it increases is a relationship I expected,

\footnotetext{
${ }^{6}$ For research on the difference of how blame it placed victims of hate crimes by individuals who score high and low on the ATLG scale see Lyons 2006.
} 
and I surmise that the more homophobic a person is, generally, the more apathetic they are towards LGBT individuals, thus causing less arousal, which, in turn, decreases their need for involvement. Ungar (1979) stated that a stigmatized individual - a homosexual in this case - may be seen with reduced attractiveness and that decreasing helping, which would fall in line with this result.

The physical intervention model yields interesting results. Those individuals in condition $\mathrm{Ho} / \mathrm{He} / 10$ had significantly lower physical intervention rates than those in the reference group $\mathrm{He} / \mathrm{Ho} / \mathrm{A}$. On one hand, this result shows support for the bystander effect since $\mathrm{Ho} / \mathrm{He} / 10$ is receiving less physical intervention than $\mathrm{He} / \mathrm{Ho} / \mathrm{A}$. However, $\mathrm{Ho} / \mathrm{He} / 10$, receives significantly less physical intervention than all other experimental conditions. A reason why the $\mathrm{Ho} / \mathrm{He} / 10$ receives the least physical intervention may be found in Ungar's (1979) work. Ungar (1979) surmises that a stigmatized individual creates a situation that makes the costs of helping more apparent, and this may be influencing this condition. In addition to the stigmatized individual in the scenario, the cost of physical intervention may be translating to the participants as much more risky than the other two intervention types. Finally, physical intervention may be interpreted has being physically aggression with the perpetrator of the scenario, which may dissuade intervention because the would-be intervener does not want to be seen as the perpetrator or as homophobic.

The implications for these results are broad. The influence of bias does have an impact when the sexual orientation of fight participants is known, and this may lay the foundation to more research on other biases and individual characteristics. Since a bias has shown to be influential in bystander intervention, this shows a need to explore this 
variable in other situations. A study exploring varying levels of severity and bias may show a scenario where human well-being or apathy wins out.

\section{Controlling Variables}

Results from the second set of regressions show the same result that males are more likely to intervene generally and physically than females. Participant's sexual orientation does not have a significant effect on general, physical, or verbal intervention, which is not what previous research found. Previous research has stated that individuals are more likely to help those who they see as their in-group opposed to those in their outgroup ${ }^{7}$. SDS scores repeated the results for these three regressions that were found in the first analysis.

\section{Analysis 3: The Interactive Effect of Bias within Conditions}

For the conditions where the perpetrator and victim's sexual orientations differ conditions 3,4,5, and 6 - a closer analysis was completed to explore if the strength of bias fluctuates from one condition to the next. A total of twelve regressions are completed and were organized by type of intervention and then condition (See Table 3).

The ATLG score has a significant negative relationship with all four conditions for general intervention $-\mathrm{He} / \mathrm{Ho} / \mathrm{A}\left(z^{*}=-2.95, \mathrm{p}=.003\right), \mathrm{Ho} / \mathrm{He} / \mathrm{A}\left(z^{*}=-2.41, \mathrm{p}=.016\right)$, $\mathrm{Ho} / \mathrm{He} / 10\left(z^{*}=-2.09, \mathrm{p}=.037\right), \mathrm{He} / \mathrm{Ho} / 10\left(z^{*}=-4.47, \mathrm{p}<.0001\right)$. In regards to physical intervention, ATLG score has a significant negative influence in the condition where $\mathrm{He} / \mathrm{Ho} / \mathrm{A}\left(z^{*}=-1.96, p=.050\right)$. ATLG scores did not significantly affect any of the other three conditions for physical intervention $-\mathrm{Ho} / \mathrm{He} / \mathrm{A}\left(z^{*}=-0.12, p=.906\right), \mathrm{Ho} / \mathrm{He} / 10\left(z^{*}=\right.$ $=-0.43, p=.664), \mathrm{He} / \mathrm{Ho} / 10\left(z^{*}=-1.46, p=.143\right)$. Verbal intervention is significantly

\footnotetext{
${ }^{7}$ For research on how helping behaviors are affected by in-group/out-group status of the victim see Levine et al. 2002.
} 
influenced by ATLG scores with all four conditions showing a negative relationship $\mathrm{He} / \mathrm{Ho} / \mathrm{A}\left(z^{*}=-2.95, p=.003\right), \mathrm{Ho} / \mathrm{He} / \mathrm{A}\left(z^{*}=-2.41, p=.016\right), \mathrm{Ho} / \mathrm{He} / 10\left(z^{*}=-2.09, p=\right.$ $.037), \mathrm{He} / \mathrm{Ho} / 10\left(z^{*}=-4.47, p<.0001\right)$.

The control variables - sex, sexual orientation, and SDS - did show significance with influencing the different types of intervention. Sex is significant with general intervention in conditions $\mathrm{He} / \mathrm{Ho} / \mathrm{A}\left(z^{*}=1.72, p=.086\right)$ and $\mathrm{Ho} / \mathrm{He} / 10\left(z^{*}=1.65, p=.099\right)$ with males being more likely to intervene than females. Males were also more likely than females to physically intervene in all four conditions $-\mathrm{He} / \mathrm{Ho} / \mathrm{A}\left(z^{*}=6.34, p<.0001\right)$, $\mathrm{Ho} / \mathrm{He} / \mathrm{A}\left(z^{*}=3.76, p<.001\right), \mathrm{Ho} / \mathrm{He} / 10\left(z^{*}=4.51, p<.001\right)$, and $\mathrm{He} / \mathrm{Ho} / 10\left(z^{*}=4.53, p<\right.$ .001). Also, males were more likely than females to verbally intervene in condition $\mathrm{Ho} / \mathrm{He} / 10\left(z^{*}=1.65, p=.099\right)$.

Sexual orientation shows significance when $\mathrm{Ho} / \mathrm{He} / 10$ with heterosexuals being more likely to physically intervene than non-heterosexuals $\left(z^{*}=2.42, p=.016\right)$. Finally, SDS shows a significant positive relationship in general $\left(z^{*}=2.79, p=.005\right)$ and verbal intervention $\left(z^{*}=2.63, p=.009\right)$ when $\mathrm{Ho} / \mathrm{He} / \mathrm{A}$ and in general $\left(z^{*}=4.28, p<.001\right)$ and verbal intervention $\left(z^{*}=4.28, p<.001\right)$ when $\mathrm{Ho} / \mathrm{He} / 10$. 
Table 3. OLS Regression of Intervention Likelihood by Type and Condition for Differentiated Dyads

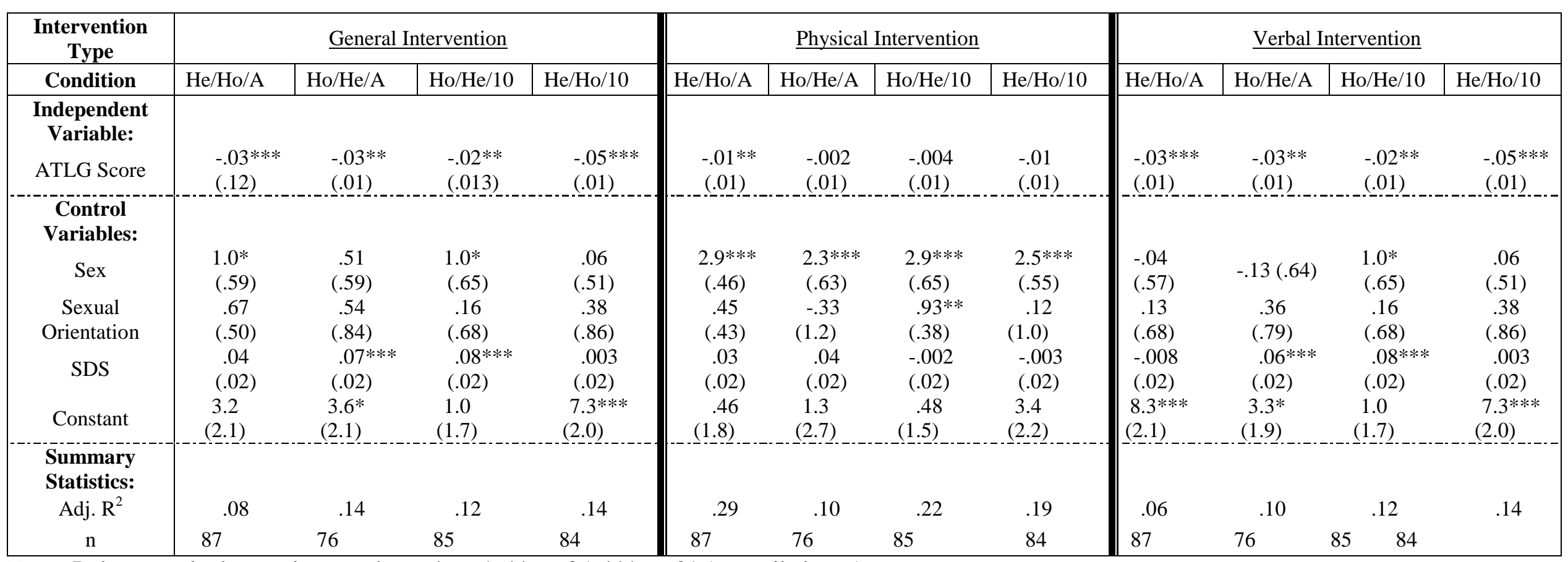

Notes: Robust standard errors in parentheses. ${ }^{*} p<.1 ; * * p<.05 ; * * * p<.01$ (two-tailed tests). 


\section{Analysis 3: Discussion and Implications}

The final analysis involves twelve regressions with the four conditions explained

for Table 2. These regressions control for ATLG score, sex, sexual orientation, and SDS. The goal of these regressions is to look at the strength of the independent and controlling variables across the four conditions to see if it is consistent or if it fluctuates.

ATLG scores have a significant negative influence on general and verbal intervention in all four conditions. Specifically, the condition that is influenced the most with general and verbal intervention is when the heterosexual is attacking the homosexual, regardless of bystander group size. However, the condition where ATLG scores have the most influence is when $\mathrm{He} / \mathrm{Ho} / 10$ with general and verbal intervention. This result shows when the homophobic participant would be with others when observing this type of event, they would be the most influenced by their bias to not intervene, and the bias of these individuals may be compounded with the anonymity that comes with there being other observers, which would explain why this condition is most influenced.

Further, the influence of the participant's ATLG score has a significant negative impact regardless of who is the perpetrator or the victim with general and verbal intervention. The only exception is that, with physical intervention, ATLG scores only influence helping in condition $\mathrm{He} / \mathrm{Ho} / \mathrm{A}$. Physical intervention implies high levels of involvement, and the reason why ATLG scores are significant when $\mathrm{He} / \mathrm{Ho} / \mathrm{A}$ but not with the other three conditions may be that there are no observers to witness one's apathy towards a gay victim. Finally, bystander group size does not seem to influence the impact of ATLG score across the conditions in general or verbal intervention.

\section{Controlling Variables}


The main goal with Table 3 is to explore the strength of bias across the four conditions; however, the control variables also show significance that needs explanation. As stated in the previous two tables, the participant's sex is a significant influencer of physical intervention with males being more likely. This result further echoes previous literature and the results mentioned above. With general intervention, sex is significant in $\mathrm{He} / \mathrm{Ho} / \mathrm{A}$ and $\mathrm{Ho} / \mathrm{He} / 10$. In $\mathrm{He} / \mathrm{Ho} / \mathrm{A}$, males may be more likely because they are the only one present, whereas females may not feel as confident in stopping a fight alone. In $\mathrm{Ho} / \mathrm{He} / 10$, males may be more likely to stop this scenario because the homosexual is the perpetrator, and the male participants may subscribe to the belief the gay males are weaker than straight males, which would raise their sense of successfulness.

The participant's SDS scores show an interesting finding. SDS only has a significantly positive relationship with general and verbal intervention when $\mathrm{Ho} / \mathrm{He} / \mathrm{A}$ and $\mathrm{Ho} / \mathrm{He} / 10$. This is extremely interesting because these socially desirable individuals are more likely to generally and verbally intervene, but only when the homosexual is attacking the heterosexual. This finding further exasperates the need to explore the complexities of SDS with helping behaviors. Finally, the participant's sexual orientation is a significant influences of physical intervention when $\mathrm{Ho} / \mathrm{He} / 10$. This finding shows that heterosexuals are more likely to intervene on behalf of a heterosexual victim than non-heterosexuals. This finding aligns with previous research that states bystanders are more likely to help the victim who they see as similar to themselves (See footnote 5).

The $\mathrm{R}^{2}$ values show much higher rates of the variance being explain in the physical intervention models. This may be occurring because all ten conditions are events of a physical fight. Specifically, it may be the act taking place that is causing this 
explanation of the variance to be higher for physical. For example, if the event involved two individuals verbally arguing, the variance for that model may increase more so than for the physical or general models.

\section{LIMITATIONS}

Like all empirical research studies, this one is not without limitations. First, this study measures the participant's perception of their behavior in a hypothetical scenario. The methodology of vignettes removes the stress, adrenaline, uncoordinated movements, and the distortion of time, vision, and sound that may play a role in intervention in an actual physical fight. Furthermore, individuals who believe they would intervene may not actually do so in a real-life situation. However, these individuals are more likely to intervene than participants who believed that they would not give assistance (Collins 2012). Further, the fact that these individuals took this survey and answered questions about their behavior increases their likelihood of completing their reported actions (Beck 1991).

Second, the sample is also limited demographically which limits the generalizability of the findings. Aside from recruiting participants from a university population, $83 \%$ of those sampled were white, $67 \%$ were Christian, and the majority of respondents were between the ages of 18 and 20. Given the homogeneity of the university population and therefore the sample, I was unable to control for these variables, specifically race. Future research should attempt to collect data from a more diverse sample in order to explore any significant differences in bystander intervention and homophobic bias between groups. Also, $91 \%$ of the sample identified as heterosexual. While, there no relationship was found between participant sexual 
orientation and likelihood of intervention, a sample containing more homosexual participants may have yielded different results.

\section{CONCLUSION}

In this study, I examined three defined types of interventions - general, physical, and verbal. This study attempted to, and successfully found, an influence of individual bias of the bystander on helping a victim of a physical fight. I tested data to explore three main questions - (1) Does the bystander effect accurately predict bystander intervention in fights when bias is controlled for?; (2) Are homophobic individuals less likely to intervene in a physical fight with a homosexual victim?' and (3) Is the strength of bias consistent across all conditions? Through the use of vignettes, ten experimental conditions were manipulated to see how an individual's attitudes toward homosexuals affected their prosocial behavior.

Eighteen regressions were completed to explore the research questions. The first three regressions looked at all ten conditions and controlled for the participant's sex and social desirability to obtain a general sense of the sample's rates of prosocial behaviors across three types of intervention. The second set of three regressions used the four conditions where the sexual orientations differed between the perpetrator and victim, and controlled for the participant's ATLG score, sex, social desirability, and sexual orientation. The third analysis involved twelve regressions that explored the strength of ATLG scores across the four conditions where the sexual orientations of the perpetrator and victim differ.

Participants are most likely to verbally intervene, followed by generally, and physically intervene the least. This finding does align with previous research (Fischer et 
al. 2006; Axelrod and Hamilton 1981; Trivers 1971; Bhatnager and Machanda 2013). Verbal intervention may be receiving higher rates than physical intervention because of the perceived lower cost to the would-be intervener. Physical intervention implies directness that may put the intervener in harms way, whereas, verbal intervention allows for a safe distance.

The aim of this paper is to shine light on the influence of individual biases on prosocial behavior. The results show that a homophobic bias does influence the likelihood of general, physical, and verbal bystander intervention. Specifically, homophobic individuals are significantly less likely to engage in any of the analyzed forms of intervention. This finding is important because it begins to lay the foundation for a more in depth look at the individual and personal factors that affect bystander behavior. The results also show that when the participants know the sexual orientations of the victim and perpetrator and these orientations differ, bystander group size is not influential. This result brings attention to the fact that the bystander effect cannot be relied on in all situations of potential bystander intervention.

Aside from the study of sexual orientation (Ryan and Wessel 2012), the role of other individual biases and their relation to bystander (in)action have not been sufficiently explored. Future researchers should attempt to fill this void in the literature by exploring the role of racism, sexism, ageism, both individually and in tandem, on bystander behavior. These explorations will allow for a more in-depth examination of the role of individual characteristics, specifically biases, and in predicting when bystanders will or will not act. 


\section{REFERENCES}

Abbott, Nicola and Lindsey Cameron. 2014. "What Makes a Young Assertive Bystander? The Effect of Intergroup Contact, Empathy, Cultural Openness, and In-Group Bias on Assertive Bystander Intervention Intentions." Journal of Social Issues 70(1):167-82.

Anon. n.d. "SE Polk Student Who Committed Suicide Was Bullied, Mom Says." Des Moines Register. Retrieved April 5, 2016 (http://www.desmoinesregister.com/story/news/education/2015/04/29/se-polk-studentcommitted-suicide-bullied-mom-says/26599367/).

Axelrod, Robert and William Donald Hamilton. 1981. "The Evolution of Cooperation." Science 211(4489):1390-96.

Baldus, David C., George Woodworth, and Charles A. Pulaski. 1990.Equal Justice and the Death Penalty: A Legal and Empirical Analysis. Upne.

Bandura, Albert. 1986. Social Foundations of Thought and Action: A Social Cognitive Theory. Prentice-Hall, Inc. Retrieved December 30, 2015 (http://psycnet.apa.org/psycinfo/1985-98423-000/).

Banyard, Victoria L. 2008. "Measurement and Correlates of Prosocial Bystander Behavior: The Case of Interpersonal Violence." Violence and Victims 23(1):83-97.

Beck, Lisa. 1991. "Predicting dishonest actions using the theory of planned behavior." Journal of research in personality 25(11):285-301.

Baumrind, Diana. 1991. "The Influence of Parenting Style on Adolescent Competence and Substance Use.” The Journal of Early Adolescence 11(1):56-95.

Bhatnagar, Namita and Rajesh V. Manchanda. 2013. "Understanding Why and How Individuals Choose to Help Others: Indirect Reciprocal Considerations and the Moderating Role of Situation Severity." Journal of Applied Social Psychology 43(11):2185-94.

Bickman, Leonard. 1971. “The Effect of Another Bystander's Ability to Help on Bystander Intervention in an Emergency." Journal of Experimental Social Psychology 7(3):367-79.

Birch, Leann Lipps and Jane Billman. 1986. "Preschool Children's Food Sharing with Friends and Acquaintances." Child Development387-95.

Bjerring, Jens Christian, Jens Ulrik Hansen, and Nikolaj Jang Lee Linding Pedersen. 2014. "On the Rationality of Pluralistic Ignorance." Synthese 191(11):2445-70. 
Bronfenbrenner, Urie. 1979. The Ecology of Human Development: Experiments by Design and Nature. Cambridge, MA: Harvard University Press.

Cacioppo, John T., Richard E. Petty, and Mary E. Losch. 1986. “Attributions of Responsibility for Helping and Doing Harm: Evidence for Confusion of Responsibility.” Journal of Personality and Social Psychology 50(1):100.

Carlo, G., S. C. Roesch, and S. H. Koller. 1999. "Cross-National and Gender Similarities and Differences in Prosocial Moral Reasoning between Brazilian and European-American College Students."REVISTA INTERAMERICANA DE PSICOLOGIA 33(1):151-72.

Carlo, Gustavo and Brandy A. Randall. 2001. "Are All Prosocial Behaviors Equal? A Socioecological Developmental Conception of Prosocial Behavior." Advances in psychology research 2:151-70.

Chekroun, Peggy and Markus Brauer. 2002. "The Bystander Effect and Social Control Behavior: The Effect of the Presence of Others on People's Reactions to Norm Violations.” European Journal of Social Psychology 32(6):853-67.

Christy, C. A., \& Voigt, H. (1994). Bystander responses to public episodes of child abuse. Journal of Applied Social Psychology, 24(9), 824-847.

Clark, Russell D. and Larry E. Word. 1974. "Where Is the Apathetic Bystander? Situational Characteristics of the Emergency." Journal of Personality and Social Psychology 29(3):279.

Collins, Randall. 2013. "Entering and Leaving the Tunnel of Violence: Micro-Sociological Dynamics of Emotional Entrainment in Violent Interactions." Current Sociology 61(2):132-51.

Costa, Angelo Brandelli, Denise Ruschel Bandeira, and Henrique Caetano Nardi. 2013. "Systematic Review of Instruments Measuring Homophobia and Related Constructs." Journal of Applied Social Psychology 43(6):1324-32.

Costin, Susan E. and Diane C. Jones. 1992a. "Friendship as a Facilitator of Emotional Responsiveness and Prosocial Interventions among Young Children." Developmental Psychology28(5):941.

Costin, Susan E. and Diane C. Jones. 1992b. "Friendship as a Facilitator of Emotional Responsiveness and Prosocial Interventions among Young Children.” Developmental Psychology28(5):941.

Crowne, Douglas P. and David Marlowe. 1960. "A New Scale of Social Desirability Independent of Psychopathology.” Journal of consulting psychology 24(4):349.

Deković, Maja and Jan M. Janssens. 1992. "Parents' Child-Rearing Style and Child's Sociometric Status.” Developmental psychology28(5):925. 
DeLamater, John D., Daniel J. Myers, and Jessica 1. Collett. 2014. Social Psychology. $8^{\text {th }}$ ed. Westview Press.

Diggory, J. C., \& Diggory, J. C. (1966). Self-evaluation: Concepts and studies. Wiley New York.

Dilks, Lisa M., Tucker S. McGrimmon, and Shane R. Thye. 2015. "Status, Emotional Displays, and the Relationally-Based Evaluation of Criminals and Their Behavior." Social science research 50:246-63.

Dovidio, John F., Jane A. Piliavin, Samuel L. Gaertner, David A. Schroeder, and Russell D. Clark III. 1991. "The Arousal: Cost-Reward Model and the Process of Intervention: A Review of the Evidence."

Dovidio, John F., Jane Allyn Piliavin, David A. Schroeder, and Louis Penner. 2006. The Social Psychology of Prosocial Behavior.Lawrence Erlbaum Associates Publishers.

Eagly, Alice H. and Maureen Crowley. 1986. "Gender and Helping Behavior: A MetaAnalytic Review of the Social Psychological Literature." Psychological bulletin 100(3):283.

Eisenberg, Nancy. 1986. "Altruistic Cognition, Emotion, and Behavior."Hillsdale, NJ, Erlbaum). EISENBERG, N., CAMERON, E., PASTERNACK, j. \& TRYON, K.(1988) Behavioural and SOCiOCOgnitive correlates of ratings of prosocial behaviour and sociometric status, Journal of Genetic Psychology 149:5-15.

Eisenberg, Nancy. 2014.Altruistic Emotion, Cognition, and Behavior (PLE: Emotion). Psychology Press.

Eisenberg, Nancy, Richard A. Fabes, and Tracy L. Spinrad. 1998a. "Prosocial Development." Handbook of child psychology.

Eisenberg, Nancy, Richard A. Fabes, and Tracy L. Spinrad. 1998b. "Prosocial Development." Handbook of child psychology.

Fischer, Donald G. and Carol Fick. 1993. "Measuring Social Desirability: Short Forms of the Marlowe-Crowne Social Desirability Scale.” Educational and Psychological Measurement53(2):417-24.

Fischer, Peter et al. 2011. "The Bystander-Effect: A Meta-Analytic Review on Bystander Intervention in Dangerous and Non-Dangerous Emergencies."Psychological bulletin137(4):517.

Fischer, Peter, Tobias Greitemeyer, Fabian Pollozek, and Dieter Frey. 2006. "The Unresponsive Bystander: Are Bystanders More Responsive in Dangerous Emergencies?"'European journal of social psychology 36(2):267-78. 
Franzen, Axel. 2013. “The Volunteer's Dilemma: Theoretical Models and.”Resolving social dilemmas: Dynamic, structural, and intergroup aspects 135.

Garcia, Stephen M., Kim Weaver, Gordon B. Moskowitz, and John M. Darley. 2002a. "Crowded Minds: The Implicit Bystander Effect." Journal of personality and social psychology 83(4):843.

Garcia, Stephen M., Kim Weaver, Gordon B. Moskowitz, and John M. Darley. 2002b. "Crowded Minds: The Implicit Bystander Effect." Journal of personality and social psychology 83(4):843.

Greitemeyer, Tobias and Dirk Mügge. 2013. "Rational Bystanders.” British Journal of Social Psychology52(4):773-80.

Greitemeyer, Tobias and Dirk O. Mügge. 2014. "Video Games Do Affect Social Outcomes a Meta-Analytic Review of the Effects of Violent and Prosocial Video Game Play." Personality and Social Psychology Bulletin0146167213520459.

Harari, Herbert, Oren Harari, and Robert V. White. 1985. "The Reaction to Rape by American Male Bystanders.”The Journal of social psychology 125(5):653-58.

Herek, Gregory M. 1988. “Heterosexuals' Attitudes toward Lesbians and Gay Men: Correlates and Gender Differences." Journal of Sex Research 25(4):451-77.

Herek, Gregory M. 1994. “Assessing Heterosexuals' Attitudes toward Lesbians and Gay Men: A Review of Empirical Research with the ATLG Scale."

Herek, G. M. (1998). Attitudes toward lesbians and gay men scale. Handbook of SexualityRelated Measures, 392-394.

Holcomb, Jefferson E., Marian R. Williams, and Stephen Demuth. 2004. "White Female Victims and Death Penalty Disparity Research.”Justice Quarterly21(4):877-902.

Knight, G. P., M. E. Bernal, and G. Carlo. 1995. "Socialization and the Development of Cooperative, Competitive, and Individualistic Behaviors among Mexican American Children.” Pp. 85-102 in Meeting the challenge of linguistic and cultural diversity in early childhood education, vol. 6.

Knight, George P., Elaine Morton Bohlmeyer, Holli Schneider, and Jerry D. Harris. 1993. "Age Differences in Temporal Monitoring and Equal Sharing in a Fixed-Duration Sharing Task." British journal of developmental psychology 11(2):143-58.

Knight, George P., Lora G. Johnson, Gustavo Carlo, and Nancy Eisenberg. 1994. “A Multiplicative Model of the Dispositional Antecedents of a Prosocial Behavior: 
Predicting More of the People More of the Time." Journal of Personality and Social Psychology 66(1):178.

Krueger, Joachim I. and Adam L. Massey. 2009. "A Rational Reconstruction of Misbehavior.” Social Cognition 27(5):786-812.

Lamborn, Susie D., Nina S. Mounts, Laurence Steinberg, and Sanford M. Dornbusch. 1991. "Patterns of Competence and Adjustment among Adolescents from Authoritative, Authoritarian, Indulgent, and Neglectful Families." Child development 62(5):1049-65.

Laner, Mary R., Mary H. Benin, and Nicole A. Ventrone. 2001. "Bystander Attitudes toward Victims of Violence: Who's Worth Helping?”Deviant Behavior 22(1):23-42.

Latane, Bibb and James M. Dabbs Jr. 1975. "Sex, Group Size and Helping in Three Cities." Sociometry180-94.

Latané, Bibb and John M. Darley. 1970. “The Unresponsive Bystander: Why Doesn’t He Help?"

Latane, Bibb and Judith Rodin. 1969. "A Lady in Distress: Inhibiting Effects of Friends and Strangers on Bystander Intervention." Journal of Experimental Social Psychology 5(2):189-202.

Latané, Bibb and John M. Darley. 1976. Help in a Crisis: Bystander Response to an Emergency. General Learning Press.

Latané, Bibb and Steve Nida. 1981. "Ten Years of Research on Group Size and Helping." Psychological Bulletin 89(2):308.

Lennon, Randy, Nancy Eisenberg, N. Eisenberg, and J. Strayer. 1987. "Gender and Age Differences in Empathy and Sympathy." Empathy and its development 195-217.

Levine, Mark. 1999. "Rethinking Bystander Nonintervention: Social Categorization and the Evidence of Witnesses at the James Bulger Murder Trial." Human Relations52(9):113355.

Levine, Mark, Clare Cassidy, Gemma Brazier, and Stephen Reicher. 2002. "SelfCategorization and Bystander Non-Intervention: Two Experimental Studies1."Journal of Applied Social Psychology 32(7):1452-63.

Levine, Mark, Amy Prosser, David Evans, and Stephen Reicher. 2005. "Identity and Emergency Intervention: How Social Group Membership and Inclusiveness of Group Boundaries Shape Helping Behavior.” Personality and Social Psychology Bulletin31(4):443-53. 
Levin, J. A., \& Nolan, J. (2011). The violence of hate: Confronting racism, anti-Semitism, and other forms of bigotry. Pearson Higher Ed.

Lurigio, Arthur J. 2015. "Crime Narratives, Dramatizations, and the Legacy of the Kitty Genovese Murder A Half Century of Half Truths." Criminal Justice and Behavior0093854814562954.

Lyons, Christopher J. 2006. "Stigma or Sympathy? Attributions of Fault to Hate Crime Victims and Offenders." Social Psychology Quarterly69(1):39-59.

Manning, Rachel, Mark Levine, and Alan Collins. 2007. "The Kitty Genovese Murder and the Social Psychology of Helping: The Parable of the 38 Witnesses." American Psychologist 62(6):555.

Merrens, Matthew R. 1973. "Nonemergency Helping Behavior in Various Sized Communities." The Journal of Social Psychology90(2):327-28.

Nicksa, Sarah C. 2013. “Bystander's Willingness to Report Theft, Physical Assault, and Sexual Assault: The Impact of Gender, Anonymity, and Relationship with the Offender." Journal of interpersonal violence0886260513505146.

Nuñez, N., S. M. McCrea, and S. E. Culhane. 2011. "Jury Decision Making Research: Are Researchers Focusing on the Mouse and not the Elephant in the Room?" Behavioral Sciences \& the Law 29:439-451.

Obergefell v. Hodges, 14 U.S. 556 (2015).

Parker, Ian. 2012. "The Story of a Suicide.” The New Yorker. Retrieved April 5, 2016 (http://www.newyorker.com/magazine/2012/02/06/the-story-of-a-suicide).

Penner, Louis A., John F. Dovidio, Jane A. Piliavin, and David A. Schroeder. 2005. "Prosocial Behavior: Multilevel Perspectives.”Annu. Rev. Psychol.56:365-92.

Piliavin, J. A., \& Charng, H.-W. (1990). Altruism: A review of recent theory and research. Annual Review of Sociology, 27-65.

Piliavin, Jane A., John F. Dovidio, Samuel L. Gaertner, and Russell D. Clark. n.d. Ill (1981), Emergency Intervention. New York: Academic Press.

Rayburn, Nadine Recker, Margaret Mendoza, and Gerald C. Davidson. 2003. 'Bystanders' Perceptions of Perpetrators and Victims of Hate Crime An Investigation Using the Person Perception Paradigm.” Journal of Interpersonal Violence 18(9):1055-74.

Roberts, A., \& Lyons, C. J. (2009). Victim-offender racial dyads and clearance of lethal and nonlethal assault. Journal of Research in Crime and Delinquency, 46(3), 301-326. 
Ross, Abraham S. 1971. "Effect of Increased Responsibility on Bystander Intervention: The Presence of Children.”Journal of Personality and Social Psychology19(3):306.

Rossi, Peter Henry and Steven L. Nock. 1982. Measuring Social Judgments: The Factorial Survey Approach. SAGE Publications, Incorporated.

Ryan, Ann Marie and Jennifer Leah Wessel. 2012. "Sexual Orientation Harassment in the Workplace: When Do Observers Intervene?"Journal of Organizational Behavior 33(4):488-509.

Schroeder, David A., Louis A. Penner, John F. Dovidio, and Jane A. Piliavin. 1995.The Psychology of Helping and Altruism: Problems and Puzzles. McGraw-Hill.

Schwartz, Shalom H. and Avi Gottlieb. 1976. "Bystander Reactions to a Violent Theft: Crime in Jerusalem."Journal of Personality and Social Psychology34(6):1188.

Sears, D. O. (1967). Social anxiety, opinion structure, and opinion change. Journal of Personality and Social Psychology, 7(2p1), 142.

Shaffer, David R., Mary Rogle, and Clyde Hendrlck. 1975. "Intervention in the Library: The Effect of Increased Responsibility on Bystanders' Willingness to Prevent a Theft." Journal of Applied Social Psychology5(4):303-19.

Shotland, R. Lance and Margret K. Straw. 1976. "Bystander Response to an Assault: When a Man Attacks a Woman.” Journal of Personality and Social Psychology 34(5):990.

Smith, Ronald E., Lisa Smythe, and Douglas Lien. 1972. "Inhibition of Helping Behavior by a Similar or Dissimilar Nonreactive Fellow Bystander."

Snyder, Mark and William Ickes. 1985. "Personality and Social Behavior."Handbook of social psychology 2:883-947.

Solomon, Linda Zener, Henry Solomon, and Ronald Stone. 1978. "Helping as a Function of Number of Bystanders and Ambiguity of Emergency." Personality and Social Psychology Bulletin 4(2):318-21.

Staub, Ervin. 1970. "A Child in Distress: The Influence of Age and Number of Witnesses on Children's Attempts to Help." Journal of Personality and Social Psychology 14(2):130.

Staub, Ervin. 1979. Positive Social Behavior and Morality, Volume II: Socialization and Development. Taylor \& Francis.

Staub, Ervin. 2013. Positive Social Behavior and Morality: Social and Personal Influences. Elsevier. 
Steffensmeier, Darrell and John H. Kramer. 1982. "Sex-Based Differences in the Sentencing of Adult Criminal Defendants: An Empirical Test and Theoretical Overview."Sociology \& Social Research.

Strahan, Robert and Kathleen C. Gerbasi. 1972. "Short, Homogeneous Versions of the Marlowe-Crowne Social Desirability Scale." Journal of clinical psychology.

Tice, Dianne M. and Roy F. Baumeister. 1985. "Masculinity Inhibits Helping in Emergencies: Personality Does Predict the Bystander Effect." Journal of Personality and Social Psychology 49(2):420.

The Globe and Mail. 2012. "Anti-Bullying Bill Passes, Clearing Way for Gay-Straight Alliances in Ontario Schools." The Globe and Mail. Retrieved April 5, 2016 (http://www.theglobeandmail.com/news/politics/anti-bullying-bill-passes-clearing-wayfor-gay-straight-alliances-in-ontario-schools/article4231542/).

The Huffington Post. 2013. "Gay Teen Taken Off Life Support After Hanging Himself On Playground." The Huffington Post. Retrieved April 5, 2016 (http://www.huffingtonpost.com/2013/01/29/jadin-bell-gay-oregon-teen-hanging-suicidelife-support-_n_2576404.html).

Trivers, Robert L. 1971. "The Evolution of Reciprocal Altruism.” Quarterly review of biology 35-57.

Underwood, Bill and Bert Moore. 1982. "Perspective-Taking and Altruism."Psychological bulletin91(1):143.

Ungar, Sheldon. 1979. "The Effects of Effort and Stigma on Helping." The Journal of Social Psychology107(1):23-28.

Walton, M. D., Sachs, D., Ellington, R., Hazlewood, A., Griffin, S., \& Bass, D. (1988). Physical stigma and the pregnancy role: Receiving help from strangers. Sex Roles, 18(56), 323-331.

Walton, M. D., Sachs, D., Ellington, R., Hazlewood, A., Griffin, S., \& Bass, D. (1988). Physical stigma and the pregnancy role: Receiving help from strangers. Sex Roles, 18(56), 323-331.

Whiting, Beatrice and Carolyn Pope Edwards. 1974. "A Cross-Cultural Analysis of Sex Differences in the Behavior of Children Aged Three through Eleven."Annual progress in child psychiatry and child development 32-49.

Wisely, Nancy. 2007. "Prosocial Behavior.” Blackwell Encyclopedia of Sociology. Blackwell Publishing. 


\section{APPENDIX A}

\section{Experimental Condition 4:}

You are exiting a bar downtown alone, and you are making your way home. You turn down an alley and see one male, who is homosexual, yelling at another male, who is heterosexual. The homosexual yells, "Ay yo, asshole! You're a God damned disgrace! Go kill yourself!" The heterosexual male starts to walk away, but then the homosexual male walks up and punches him. This starts a fight where they are both throwing punches. Both males are white, of average height, about 5'11, and average weight, about 170 pounds. You are the only observer of this fight, and you do not know either of the individuals. 